\title{
Development of a Novel Characterisation Methodology for the Aerodynamic Coefficients of a Tractor-Trailer Unit Based on Relative Flow Angles and Vehicle Dimensions
}

\author{
Vihar Malviya ${ }^{1} \cdot$ Taimoor Asim $^{1} \cdot$ Isuru Sendanayake ${ }^{1} \cdot$ Rakesh Mishra $^{1}$
}

Received: 11 September 2017 / Accepted: 20 March 2018 / Published online: 13 April 2018

(c) The Author(s) 2018

\begin{abstract}
Tractor-trailer units are integral part of the heavy commercial vehicle industry, used globally for goods transportation. Manufacturers have been trying to design aerodynamically efficient tractor-trailer units to reduce ever increasing fuel costs. In order to investigate the aerodynamic response of tractor-trailer units, the aerodynamic forces and moments have to be determined accurately, especially under crosswind conditions. In the present study, a computational fluid dynamics-based solver has been employed to simulate the flow field around a tractor-trailer with a view to quantify the effects of side wind and size variations on aerodynamic force moment system acting on tractor-trailer combination. It has been shown that the aerodynamic forces are significantly influenced by both the geometrical and flow characteristics. The drag, lift and side forces acting on a tractor-trailer unit are highest at relative flow angles of $15^{\circ}, 30^{\circ}$ and $90^{\circ}$, respectively. Aerodynamic forces and coefficients have been enumerated for these geometrical and flow conditions, and have been used to develop novel semi-empirical correlations for the aerodynamic coefficients for the tractor-trailer unit. These correlations have been shown to predict the aerodynamic coefficients for various vehicle dimensions under a range of flow conditions with reasonable accuracy.
\end{abstract}

Keywords Heavy commercial vehicle (HCV) - Computational fluid dynamics (CFD) · Computer-aided design (CAD) . Computer-aided engineering (CAE) · Aerodynamic coefficients

$\begin{array}{ll}\text { List of symbols } \\ C_{\mathrm{D}} & \text { Drag coefficient vehicle }(-) \\ C_{\mathrm{L}} & \text { Lift coefficient of the vehicle }(-) \\ C_{\mathrm{S}} & \text { Side coefficient of the vehicle }(-) \\ C_{\mathrm{P}} & \text { Coefficient of pressure }(-) \\ l & \text { Length of the vehicle }(\mathrm{m}) \\ h & \text { Height of the vehicle }(\mathrm{m}) \\ w & \text { Width of the vehicle }(\mathrm{m})\end{array}$

Taimoor Asim

t.asim@hud.ac.uk

Vihar Malviya

u0570429@alumni.hud.ac.uk

Isuru Sendanayake

u0857384@hud.ac.uk

Rakesh Mishra

r.mishra@hud.ac.uk

1 University of Huddersfield, Queensgate, Huddersfield HD1 3DH, UK

$\begin{array}{ll}P & \text { Static gauge pressure }(\mathrm{Pa}) \\ U & \text { Flow velocity magnitude }(\mathrm{m} / \mathrm{s}) \\ \text { Greek symbols } \\ \infty & \text { Free stream } \\ \mu & \text { Dynamic viscosity of air }\left(\mathrm{N}-\mathrm{s} / \mathrm{m}^{2}\right) \\ \rho & \text { Density of air }\left(\mathrm{kg} / \mathrm{m}^{3}\right) \\ \psi & \text { Angle of the flow relative to the vehicle }\left(\mathrm{rad},{ }^{\circ}\right)\end{array}$

\section{Introduction}

The rapid development of the transport infrastructure and the automotive industry has allowed road vehicles to operate at high speeds. The heavy commercial vehicle (HCV) industry has advanced significantly over the years from having less fuel efficient vehicles to those that are much more efficient and capable of travelling at high speeds, thus considerably reducing transit times. Nevertheless, over the years, there has been only a limited change that has been witnessed 
in the overall design of tractor-trailer units. This majority of HCVs still employ box-shaped designs with large flat surfaces, which combined with the impinging flow; generate aerodynamic forces on these vehicles which may cause severe instability in the vehicles under strong side wind conditions. The vehicles thus have become extremely vulnerable to overturning in windy conditions. An HCV rollover due to crosswinds on a highway can have overwhelming effects, endangering lives and causing considerable damage to the infrastructure. In 1992, Baker and Reynolds [1] found out that there were approximately 400 wind-induced accidents in the UK, resulting in either death or injury, during the storms on 25 January 1990. Hence, the effect of crosswinds on the stability of an HCV has become a significant issue over the years.

There has been a great deal of attention given to understanding the crosswind aerodynamics of passenger cars. The aerodynamic forces acting on an $\mathrm{HCV}$ are the outcome of the complex nature of the pressure and velocity fields in the vicinity of the HCV. These aerodynamic forces are the drag $\left(F_{\mathrm{D}}\right)$, lift $\left(F_{\mathrm{L}}\right)$ and side $\left(F_{\mathrm{S}}\right)$ forces [2-5]. These forces can be mathematically expressed as:

$$
\begin{aligned}
F_{\mathrm{D}} & =\frac{1}{2} \rho V^{2} A C_{\mathrm{D}} \\
F_{\mathrm{L}} & =\frac{1}{2} \rho V^{2} A C_{\mathrm{L}} \\
F_{\mathrm{S}} & =\frac{1}{2} \rho V^{2} A C_{\mathrm{S}}
\end{aligned}
$$

where $C_{\mathrm{D}}, C_{\mathrm{L}}$ and $C_{\mathrm{S}}$ are the aerodynamic coefficients of drag, lift and side forces, respectively, $A$ is the frontal area of the vehicle and $\rho$ is the density of the fluid.

The magnitude of the aerodynamic forces being exerted on HCVs is affected by factors such as vehicular geometry and speed, relative wind velocity and flow angle, etc. It is indispensable to develop a methodology to quantify and predict the aerodynamic forces at the earliest possible design stage of the HCVs so that performance and stability considerations can be integrated in the design process.

The need for establishing interrelation between vehicle's geometrical quantification and resulting aerodynamic forcecouple system over a wide range of side wind flow conditions is necessary to inform design process at an early stage. Some applications require vehicle's geometrical quantification for styling and prototyping purposes. Calkins et al. [6] have developed a design-rule-based software framework for accelerating the product development cycle of automobiles by integrating various software-based technologies like computer-aided design (CAD), computer-aided engineering (CAE) and knowledge-based tools. Its scope includes characterisation of body exterior, weight, fuel economy, acceleration and aerodynamic drag force. The underlying mathematical principles used in developing this tool have not been discussed. Some applications of vehicle's geometrical quantification require mathematical representation of vehicle's shape with a view to quantify and optimise aerodynamic interactions of the vehicle with its flow field [7-10].

One of the earliest studies to quantify the influence of vehicle's shape on its aerodynamic characteristics has been carried out by Berta et al. [11]. Source-sink panel method has been used to numerically predict the drag force by discretising the surfaces of two bus shapes, and one car shape, into panels. However, the assumption of inviscid flow severely limits the usefulness of this methodology in real-world applications. In a more recent study, Calkins and Chan [12] have developed a single software tool for predicting the aerodynamic drag on vehicles, based on specific quantifiable surface shape parameters, like geometrical properties of surface curves and their locations. The validation of this tool has been carried out by using five full-sized automobiles in a wind tunnel test. This tool has been shown to be more effective in the early design phase of the vehicles, where these input parameters can be specified, rather than measured.

Koromilas et al. [13] applied neural network prediction techniques to quantify the aerodynamic drag force, specifically for two-box vehicle configuration. This system has been found to be fully capable of computing the drag coefficient of a vehicle. However, upon changing the shape of the vehicle, the neural network needs to be re-trained with a large database of aerodynamic results, to be fully functional. The training process requires an excessive amount of time and resources; both the input and expected output values are to be provided prior to training the network. Rho et al. [14] proposed a vehicle shape function equation for aerodynamicists to work together with vehicle stylists to predict basic aerodynamic characteristics of vehicle shapes, before expensive wind tunnel testing. The entire vehicle's geometry is divided into arbitrary boxes, or sections, instead of those defined by Calkins et al. [6] and Calkins and Chan [12]. Each of these sections is defined by a shape function. However, the shape functions discussed in this study have been developed primarily for passenger cars and therefore consist of several irrelevant parameters and relations in the context of HCVs. These parameters are simply not required for accurate quantification of HCVs, since they are invariably simple in overall geometry, compared to passenger cars, resulting in a smaller number of parameters.

Baker [15] has proposed a two-axle vehicle stability model for studying the behaviour of a vehicle under crosswinds for rollover accidents and course deviation. Several analyses based on this model use experimental results to investigate the steady state, as well as transient behaviour, of various categories of vehicles, in varying and steady crosswinds [1624]. These works include modelling of driver's behaviour, parameterisation of the risk of accidents [17,24], investi- 
gation of the impact of simulating atmospheric turbulence [12], and the effect of geometrical parameters of tractortrailer units, such as rounding of corners [18], all with varied degrees of success and accuracy. In one of these studies [15], it has been proposed that the influence of crosswinds on the drag $\left(C_{\mathrm{D}}\right)$, lift $\left(C_{\mathrm{L}}\right)$ and side $\left(C_{\mathrm{S}}\right)$ coefficients for a doubledeck Atlantean bus can be quantified by using the empirically evaluated relationships shown in equations (4-6).

$$
\begin{aligned}
& C_{\mathrm{D}}=-0.25[1+2 \sin (3 \psi)] \\
& C_{\mathrm{L}}=1.5[1+\sin (3 \psi)] \\
& C_{\mathrm{S}}=3.84 \psi^{0.382}
\end{aligned}
$$

In Eq. (4), the negative sign indicates the direction of the drag force being exerted on the bus. These equations have been developed by empirical methods, on the basis of results obtained from previous experimental investigations. It is clear from these equations that they represent the variations in the aerodynamic coefficients with respect to the relative flow angle ( $\psi$, also called as yaw angle) between the bus and the flow only. This is a very interesting work as it quantifies the influence of side wind angle $\psi$ on various aerodynamic coefficients for a large bus which is rigid in shape. It can be seen that additional influence of wind angle is quantified as a sine function for both drag and lift coefficients, whereas for side force this effect is obtained as a power function. Equations (4)-(6) are unlikely to be useful for establishing aerodynamic interaction between air flow and tractor-trailer combinations because of the flexible nature of tractor-trailer combinations with a variety of additional flow channels through the tractortrailer body unlike a large rigid bus for which the above equations have been developed. Furthermore tractor-trailer combinations come in a variety of sizes and especially for large flow angles it may be possible to have additional effects of dimensions of tractor-trailer on aerodynamic flow characteristics which are not seen in Eqs. (4)-(6).

The existing methods of predicting aerodynamic coefficients are somewhat primitive, limited in application, and restricted to small relative flow angles. A methodology to bridge these gaps needs to be formulated so that the aerodynamic coefficients can be predicted for a variety of tractor-trailer geometries under a wide range of flow conditions. Hence, in the present work, a detailed investigation on the aerodynamic characteristics of different sized tractor-trailer vehicles under various crosswind conditions has been carried out. Computational fluid dynamics (CFD)based techniques have been employed to analyse vehicle's response in such conditions. Alongside detailed flow field characteristics on important surfaces of a tractor-trailer vehicle, novel semi-empirical correlations have been developed to predict the aerodynamic forces/coefficients acting on HCVs with different dimensions, under a wide range of flow conditions.

\section{Scope of the Work}

Based on the key operational and legal restrictions applicable for HCVs, prevalent in the UK and mainland Europe, a realistic and practical tractor-trailer model has been chosen in the present investigation, removing many simplifications associated with earlier studies $[25,26]$. The restrictions on the maximum length $(l)$, width $(w)$ and height $(h)$ are 16.5, 2.6 and $4.8 \mathrm{~m}$, respectively. Similarly, the restriction on minimum tractor-trailer gap, at any given position, is $0.2 \mathrm{~m}$. Figure 1a, $\mathrm{b}$ depicts both the numerical and real-world tractor-trailer units of length $=16.28 \mathrm{~m}$, height of $4.8 \mathrm{~m}$ and width of $2.6 \mathrm{~m}$, with a gap length of $0.2 \mathrm{~m}$.

In order to quantify the aerodynamic effects in terms of the relative flow angle and vehicle's dimensions, tractortrailer configurations corresponding to three vehicle heights and lengths have been numerically simulated over a wide range of flow conditions. The most common trailer units in the UK have heights of $4.4 \mathrm{~m}$ (single deck, same height as that of the tractor); 4.6 and $4.8 \mathrm{~m}$ (double deck, maximum height) and hence have been chosen for further analysis. Similarly, three different tractor-trailer unit lengths are commonly seen in the UK, having lengths of $15.28,15.78$ and $16.28 \mathrm{~m}$, respectively. A constant vehicle width of $2.6 \mathrm{~m}$ has been used for all the configurations investigated, representing most common cases, as HCV manufacturers tend to build vehicles with maximum allowed width of $2.6 \mathrm{~m}$, to achieve maximum loading capacity. The edges of the tractor have been rounded with a radius of $0.1 \mathrm{~m}$. The vehicle's length and height considered in these configurations have been converted to non-dimensional form on the basis of vehicle's width. These combinations, and the respective dimensions, have been listed in Table 1 .

The third geometrical configuration in Table 1 (i.e. length and height of 16.28 and $4.8 \mathrm{~m}$, respectively) will be treated as the baseline model in the present study, and comparison will be made against the results obtained for this particular configuration.

For the purpose of investigating the effect of the relative flow angle between the tractor-trailer unit and the air flow on flow field characteristics, a range of relative flow angles, varying from $0^{\circ}$ to $180^{\circ}$ in $15^{\circ}$ increments have been chosen for carrying out steady-state CFD simulations. The flow distribution in the vicinity of the vehicle, and the associated aerodynamic forces and coefficients, for various geometrical and flow conditions have been numerically analysed.

\section{Numerical Formulation}

Ansys 17.0, a computational fluids dynamics-based solver, has been used in the present study for the aerodynamic analysis of air flow around the tractor-trailer units summarised 


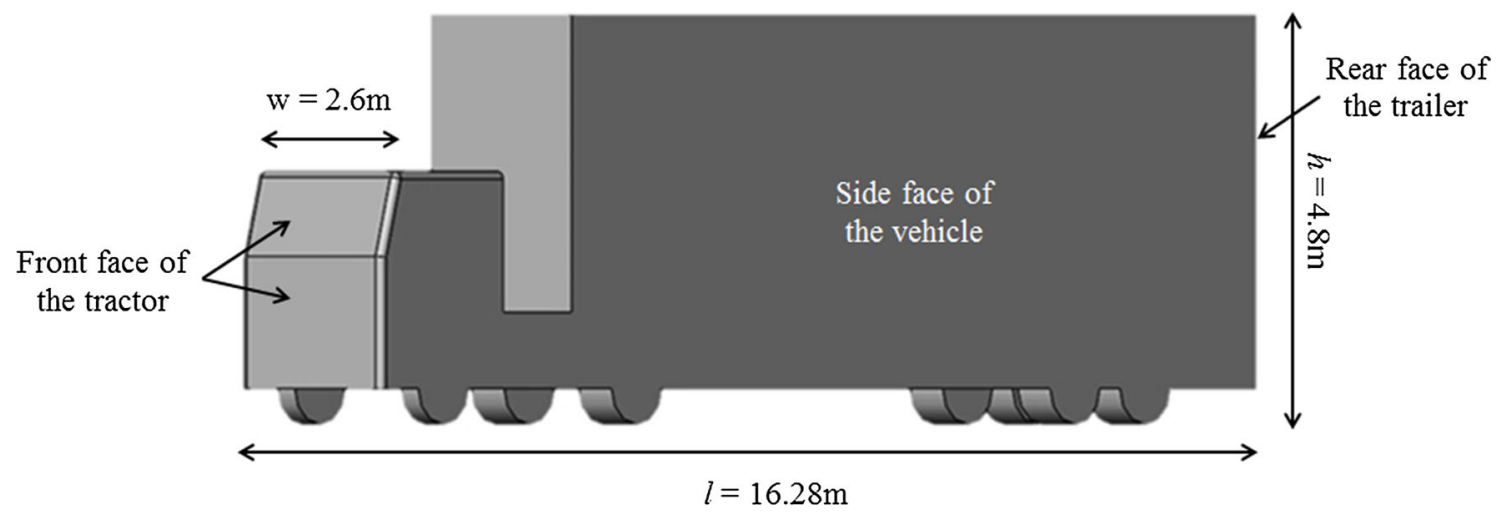

(a)

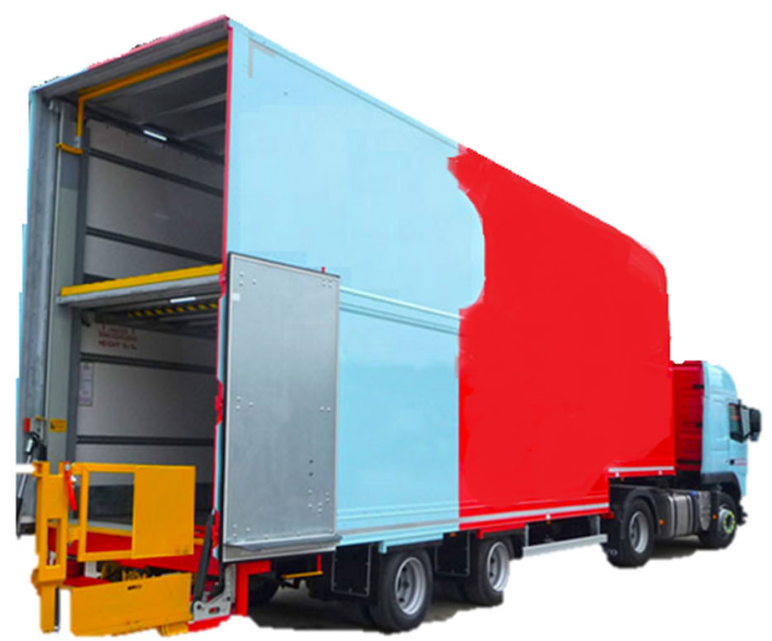

(b)

Fig. 1 Tractor-trailer units of height $4.8 \mathrm{~m}$, a numerical model, $\mathbf{b}$ real-world unit

Table 1 Geometrical characterisation of the tractor-trailer unit

\begin{tabular}{llll}
\hline $\begin{array}{l}\text { Vehicle length } \\
l(\mathrm{~m})\end{array}$ & $\begin{array}{l}\text { Vehicle height } \\
h(\mathrm{~m})\end{array}$ & $\begin{array}{l}\text { Non-dimensional length } \\
l / \mathrm{w}(-)\end{array}$ & $\begin{array}{l}\text { Non-dimensional height } \\
h / \mathrm{w}(-)\end{array}$ \\
\hline 15.28 & 4.8 & 5.8769 & 1.8462 \\
15.78 & 4.8 & 6.0692 & 1.8462 \\
16.28 & 4.4 & 6.2615 & 1.6923 \\
16.28 & 4.6 & 6.2615 & 1.7692 \\
16.28 & 4.8 & 6.2615 & 1.8462 \\
\hline
\end{tabular}

in Table 1. The details of the numerical formulations are discussed hereafter.

\subsection{Computational Domain}

A three-dimensional flow domain has been generated around the different models of the tractor-trailer units considered in the present study. As shown in Fig. 2, the length of the flow domain is $179 \mathrm{~m}$, such that the distance between the front surface of the tractor and the velocity inlet is three times the length of the tractor-trailer unit. Similarly, the dis- tance between the pressure outlet of the flow domain and the rear surface of the trailer is seven times the length of the tractor-trailer model. It has been observed that a distance of $7 l$ ( $l$ being the length of the tractor-trailer unit) is sufficient to prevent the downstream-imposed constant pressure of 101,325 Pa (ambient atmospheric pressure) condition from having an upstream effect on the pressure field in the region of interest (i.e. in the vicinity of the tractor-trailer model). The width of the flow domain is $18.2 \mathrm{~m}$, such that the side surfaces of the domain (i.e. domain walls) are at a distance of $3 l$ from the side surfaces of the model. Similarly, 


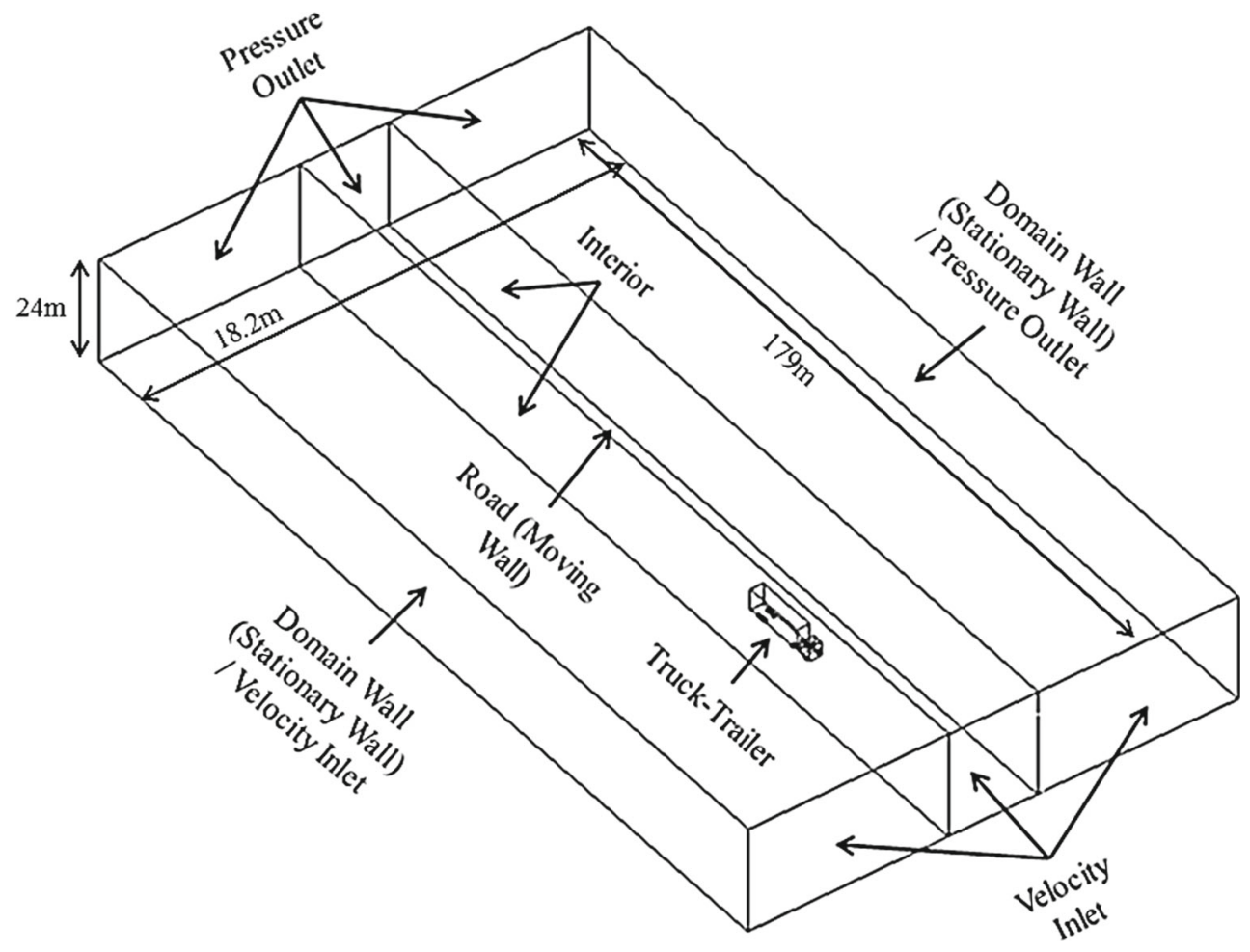

Fig. 2 Description of the flow domain

the height of the flow domain is $24 \mathrm{~m}$, such that the distance between the top surface of the domain and the top surface of the tractor-trailer model is at least $4 h$ (where $h$ is the height of the tractor-trailer model). These dimensions of the flow domain have been recommended in many previous research studies for bluff bodies [7-10,27,28].

The front face of the domain, ahead of the tractor-trailer model, has been defined as a velocity inlet with a uniform flow entering the domain at a constant velocity of $25 \mathrm{~m} / \mathrm{s}$ $(90 \mathrm{~km} / \mathrm{h}, 56 \mathrm{mph})$ for head-on wind conditions, representing the cruising speed of the tractor-trailer units. The rear face of the domain (i.e. behind the model) has been defined as a pressure outlet at a constant atmospheric pressure of $101,325 \mathrm{~Pa}$ (absolute). The bottom face of the flow domain has been defined as a moving surface (wall representing road), synchronised with the inlet flow velocity at $25 \mathrm{~m} / \mathrm{s}$ in the stream-wise direction to simulate real life road conditions. The wheels of the model have been defined as rotating walls, with an angular velocity of $48.75 \mathrm{rad} / \mathrm{s}$ to synchronise them with the relative motion of the vehicle. The crosssectional blockage ratio has been found to be $3.1 \%$, based on flow domain's cross-sectional area of $400.4 \mathrm{~m}^{2}$, and tractortrailer model's cross-sectional area of $12.22 \mathrm{~m}^{2}$. Since this blockage is less than $5 \%$, no corrections to the results are required [28]. In order to analyse the effects of the crosswinds on the tractor-trailer units considered, one of the side wall of the domain has been modelled as the second velocity inlet, while the other side wall of the domain has been modelled as the second pressure outlet. Hence, the inlet velocities are variable, depending on the angle of the crosswinds, while the pressure at the outlet boundaries is kept constant at atmospheric conditions.

\subsection{Spatial Discretisation of the Flow Domain}

The flow domain has been spatially discretised into an unstructured mesh of tetrahedral elements, with an element count of approximately 2.2 million. The concentration and the level of refinement of the mesh elements around the model have a substantial impact on the accuracy of CFD predictions. Hence, the mesh quality has been controlled in a manner that, in the vicinity of the vehicle, the domain consists of smaller mesh elements to capture the complex flow phenomena accurately and consequently to provide reliable results. For this purpose, the flow domain has been divided into two zones relative to mesh element size. As depicted in Fig. 3, the inner zone has been discretised into finer elements, as compared to the outer zone. This methodology allows an effective discretisation of the flow domain that leads to much more efficient use of computational resources [29,30]. Furthermore, 15 prism-shaped mesh layers have been inserted around the vehicle, having a first layer height of about $2.5 \mathrm{~mm}$, to further enhance the precision of the calculations. The resultant mesh achieved a maximum skewness of 0.6 for over $95 \%$ of the 


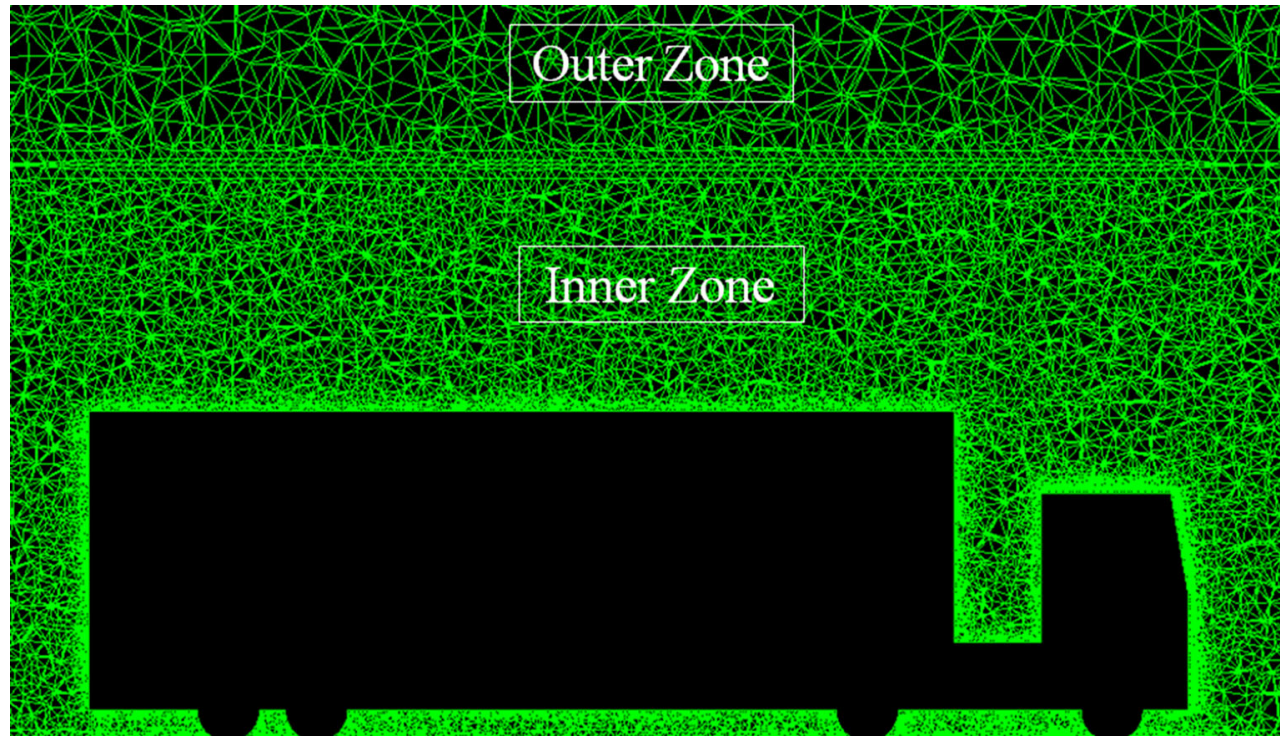

Fig. 3 Meshing within various zones of the flow domain

elements, and an aspect ratio between 1 and 2 for over $99 \%$ of the elements. It has been ensured that the $y+$ value for all the different configurations analysed in the present study (both geometrical and flow) is within the log-law region, i.e. around 30 , as suggested in many previous studies [31-33].

\subsection{Solver Settings}

Three-dimensional Reynolds averaged Navier-Stokes Eq. (7), along with the continuity Eq. (8), for incompressible flow of turbulent air around the tractor-trailer units, have been numerically solved for the in an iterative manner.

$\rho \bar{u}_{j} \frac{\partial \bar{u}_{i}}{\partial x_{j}}=\rho \bar{f}_{i}+\frac{\partial}{\partial x_{j}}\left[-\bar{p} \delta_{i j}+\mu\left(\frac{\partial \bar{u}_{i}}{\partial x_{j}}+\frac{\partial \bar{u}_{j}}{\partial x_{i}}\right)-\rho{\overline{u_{i} \bar{u}_{j}}}\right]$

$\frac{\partial u_{i}}{\partial x_{i}}+\frac{\partial u_{j}}{\partial x_{j}}+\frac{\partial u_{k}}{\partial x_{k}}=0$

Air turbulence has been modelled using a two-equation turbulence model, i.e. shear stress transport (SST) $k-\omega$ model. It has been shown in many previous studies that SST $k-\omega$ turbulence model is superior in accurately predicting the complex flow phenomena, which are also expected in case of tractor-trailer units [31-37]. This model comprises a blending function for near-wall treatment. Further details of SST $k-\omega$ model can be found in different texts available in literature [38-41]. A pressure-based steady-state solver has been employed in the present study with second-order upwind discretisation schemes for momentum, $k$ and $\omega$ equations for better accuracy of the predicted flow fields in around the tractor-trailer unit/s. Furthermore, SIMPLE scheme for
Table 2 Mesh independence results

\begin{tabular}{ll}
\hline Number of elements & Drag coefficient \\
\hline 520,356 & 0.51 \\
$1,560,365$ & 0.65 \\
$2,235,896$ & 0.71 \\
$4,398,521$ & 0.72 \\
\hline
\end{tabular}

pressure-velocity coupling has been used in the numerical simulations.

\subsection{Mesh Independence Tests}

In order to ensure that the numerical simulations are not influenced by the meshing controls, a mesh independence study has been carried out. The mesh has been refined by simply dividing the flow domain into additional mesh elements and thus, enhancing the resolution of the simulation. The independence of the simulation from the mesh density has been judged by the variation of the coefficient of drag force $\left(C_{\mathrm{D}}\right)$ values with number of elements. Table 2 shows the values of $C_{\mathrm{D}}$ for corresponding cases of different meshes. By examining the results, it is evident that $C_{\mathrm{D}}$ does not vary significantly beyond 2.2 million elements in the flow domain and hence has been chosen for further analysis in the present study.

\subsection{Validation of CFD Results}

The CFD predicted aerodynamic coefficients have been validated against the experimental data obtained by Coleman and Baker [18] for a tractor-trailer unit, which has differ- 


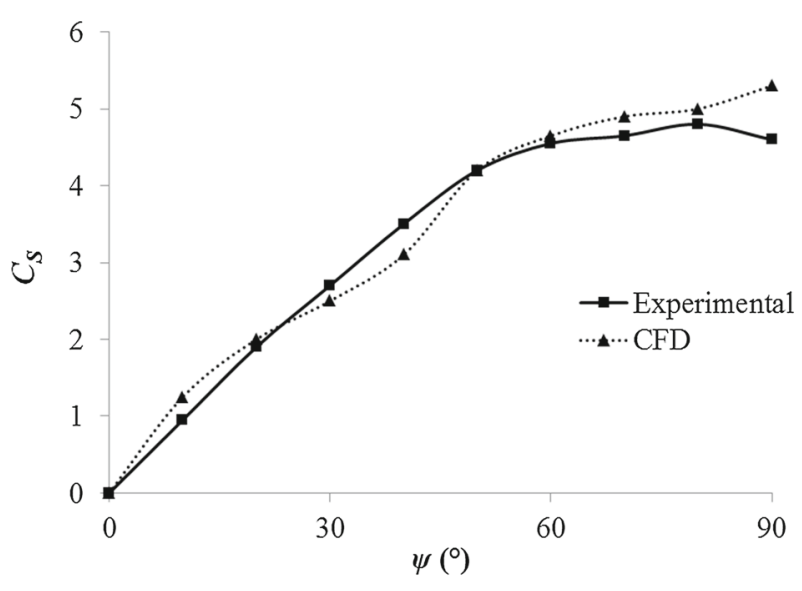

(a)

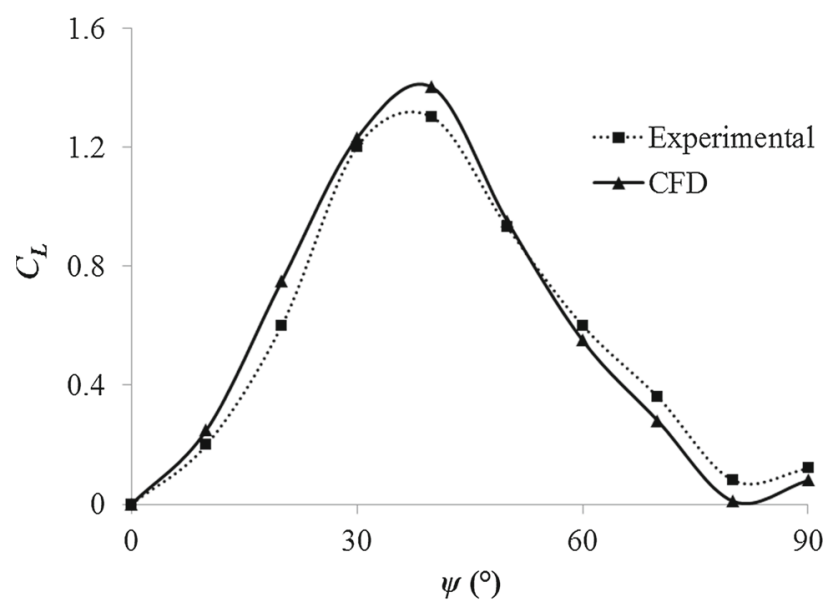

(b)

Fig. 4 Comparison of aerodynamic coefficients at various yaw angles, a side coefficient $\left(C_{\mathrm{S}}\right)$, b lift coefficient $\left(C_{\mathrm{L}}\right)$

ent geometrical parameters compared to the models under investigation in the current study. Hence, the geometrical and flow parameters are kept the same. The numerical study has been carried out in order to compare the aerodynamic coefficients obtained by CFD against the aerodynamic coefficients recorded by Coleman and Baker in order to validate the reliability of the CFD model. Lift coefficient $\left(C_{\mathrm{L}}\right)$ and side coefficient $\left(C_{\mathrm{S}}\right)$ data have been recorded for a range of yaw angles $(\psi)$ at a constant inlet flow velocity of $16.6 \mathrm{~m} / \mathrm{s}$. Figure $4 \mathrm{a}$, b depicts the variation in $C_{\mathrm{S}}$ and $C_{\mathrm{L}}$ at various yaw angles. It can be clearly seen that $C_{\mathrm{S}}$ values obtained using CFD simulations are quite low at smaller yaw angles, which then increases proportionally. This trend observed in CFD data is in-line with the published experimental data recorded by Coleman and Baker. Furthermore, the $C_{\mathrm{L}}$ values rise gradually with the yaw angle, until it reaches $40^{\circ}$, depicting the peak of the $C_{\mathrm{L}}$. When the yaw angle reaches $40^{\circ}$, the $C_{\mathrm{L}}$ then decreases as the flow angle continues to increase. As the yaw angle reaches $80^{\circ}$, the $C_{\mathrm{L}}$ once again begins to rise. It can be seen that the CFD predicted results follows a similar trend to that of the experimental data. In both the data sets, the highest $C_{\mathrm{L}}$ values are recorded at $40^{\circ}$, which subsequently begin to decline until the lowest $C_{\mathrm{L}}$ values are obtained at $80^{\circ}$. The CFD results are in reasonable agreement with the experimental data with respect to the trends, standard error of estimate and the Chi-square between the experimental and numerical data. Standard error of estimate and the Chi-square have been calculated to be approximately $10 \%$ and 0.99 , respectively. Hence, the numerical results obtained using CFD depict no significant difference to the experimental data. This confirms that the CFD set-up used to obtain the data for the current work predicts the aerodynamic coefficients to a reasonable accuracy.

\section{Effect of Flow Angle on the Pressure Distribution on Key Surfaces of the Tractor-Trailer Unit}

Investigation of flow behaviour in the vicinity of the tractortrailer unit is essential as it provides important insight into the response of the vehicle's flow field to variations in the free stream flow. In the present study, these variations are characterised by change in flow angle about the yaw (vertical, y) axis. A study of the pressure distribution has been carried out to gain an understanding of this aerodynamic behaviour. These pressure values have been represented in non-dimensional form, as coefficient of pressure $\left(C_{\mathrm{P}}\right)$, which can be expressed as:

$C_{\mathrm{P}}=\frac{P-P_{\infty}}{0.5 \rho U_{\infty}^{2}}$

where $P$ is the local static pressure (in $P a$ ), $P_{\infty}$ is the static pressure at free-stream location (upstream the model where there is no disturbance in the pressure field; in $\mathrm{Pa}$ ), $\rho$ is air density (in $\mathrm{kg} / \mathrm{m}^{3}$ ), and $U_{\infty}$ is the free-stream flow velocity magnitude (in $\mathrm{m} / \mathrm{s}$ ). In the present study, $P_{\infty}$ has been considered as the ambient atmospheric pressure of $101325 \mathrm{Pag}$, $\rho$ has been specified as $1.225 \mathrm{~kg} / \mathrm{m}^{3}$, and $U_{\infty}$ has been considered the same as the flow velocity at the inlet of the flow domain. Note that the analysis presented in this section of the study (i.e. effects of crosswinds) has been carried out on the baseline tractor-trailer model. The other geometrical models (with varying lengths and heights) have been analysed in Sect. 6.1 of this study (i.e. effects of vehicle size).

Figure 5 depicts the distribution of coefficient of pressure $\left(C_{\mathrm{P}}\right)$ at the middle plane of tractor-trailer in the width direction at a relative flow angle $\psi=0^{\circ}$. Due to the head-on wind, the pressure on the front of the tractor is expected to be high, as can be seen in the figure. However, due to flow separation on the top front edge of the tractor, the pressure in 


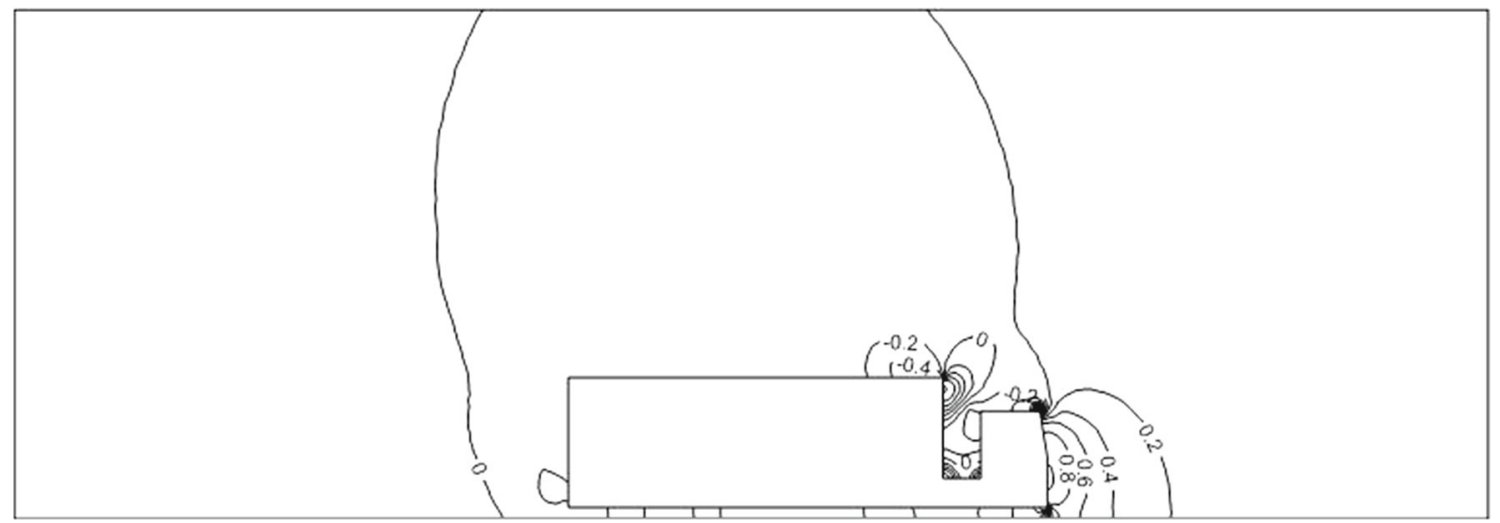

Fig. 5 Variations in coefficient of pressure $\left(C_{\mathrm{P}}\right)$ at the middle plane of the tractor-trailer unit

the gap region between the tractor and the trailer is low. Some distance downstream the gap region (on the trailer surface) the flow gets re-attached to the trailer surface/s.

In order to analyse the pressure field in depth, the pressure distribution on key surfaces of the vehicle have been analysed in the next section.

\subsection{Pressure Distribution on the Front Face of the Tractor}

The front face of the tractor is a significant surface on the vehicle as it experiences the direct impact of oncoming free stream flow at low angles of attack, and contributes dominantly to the overall pressure drag acting on the vehicle. Hence, an in-depth analysis of the variations in the pressure on this face is essential for a better understanding of the aerodynamic behaviour of the model. In this section, the pressure distribution on the front face of the tractor has been discussed for flow angles of $0^{\circ}, 45^{\circ}, 90^{\circ}, 150^{\circ}$ and $180^{\circ}$.

Figure 6 depicts the distribution of coefficient of pressure $\left(C_{\mathrm{P}}\right)$ on the front face of the tractor at various relative flow angles considered in the present study. The front face of the tractor can be divided into two sections: one being the lower $60 \%$ of the front section (perpendicular to head winds) and the other being the upper $40 \%$ inclined wind screen section. Figure 6 a corresponds to $\psi=0^{\circ}$, where it is expected that the head-on wind will get separated from the peripheral edges of the front face of the tractor. Hence, it can be seen in the figure that there is a relatively low-pressure region present at the periphery of the front face. Moreover, it is also expected that the lower section of the tractor (which is perpendicular to the flow) exhibits higher pressure as compared to the wind screen (upper) section, where the flow is expected to accelerate due to the angle that wind screen makes with the incident flow. Due to the acceleration of the flow over the wind screen, the pressure is expected to be lower as compared to the lower front section of the tractor. It is evident from the figure that the pressure decreases from the lower towards the upper section (wind screen) of the tractor, as expected.

As the yaw angle increases, and the flow is expected to approach the tractor from the left side in the figures, it is expected that the separation will now take place from the right hand side edges of the front face, which is clearly visible in Fig. $6 \mathrm{~b}$ for $\psi=45^{\circ}$. Further increase in the yaw angle to $90^{\circ}, 150^{\circ}$ and $180^{\circ}$ is expected to significantly decrease the pressure on the front face of the tractor, as the flow is no longer approaching this surface. A very non-uniform pressure distribution can be seen in Fig. 6c-e, with the decrease in pressure due to the increase in the yaw angle.

\subsection{Pressure Distribution on the Side Face of the Vehicle}

The side faces of the tractor-trailer unit are important in the overall flow field analysis of the vehicle. This is because these faces are the largest faces on the surface of the entire vehicle. Moreover, the right side has greater significance due to the fact that this face experiences the impact of the larger portion of the oncoming free stream flow at higher angles, in the present study.

Figure 7 shows the distribution of coefficient of pressure $\left(C_{\mathrm{P}}\right)$ on the right side surface of the tractor-trailer at various relative flow angles considered in the present study. The entire side face of the vehicle can be divided into two sections for simplicity: one being the tractor section and the other being trailer section, both connected together by the bridge. Figure 7 a corresponds to $\psi=0^{\circ}$, where it is expected that the head-on wind will get separated from the leading edges of the front face of the tractor and the trailer, which is expected to re-attach to the solid surfaces somewhere downstream. Hence, it can be seen in the figure that there is a low-pressure region present near the front of the tractor (right end in the figure) with $C_{\mathrm{P}} \Leftarrow-0.4$, where the flow gets separated from the surface of the tractor, causing lower pressure. This pres- 


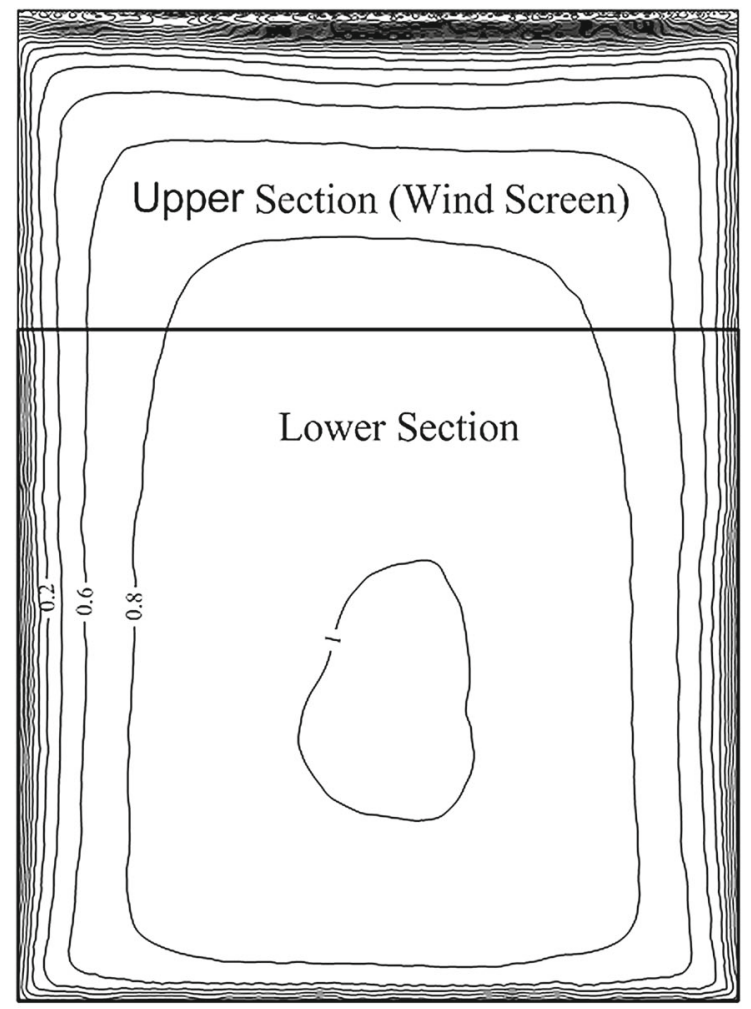

(a)

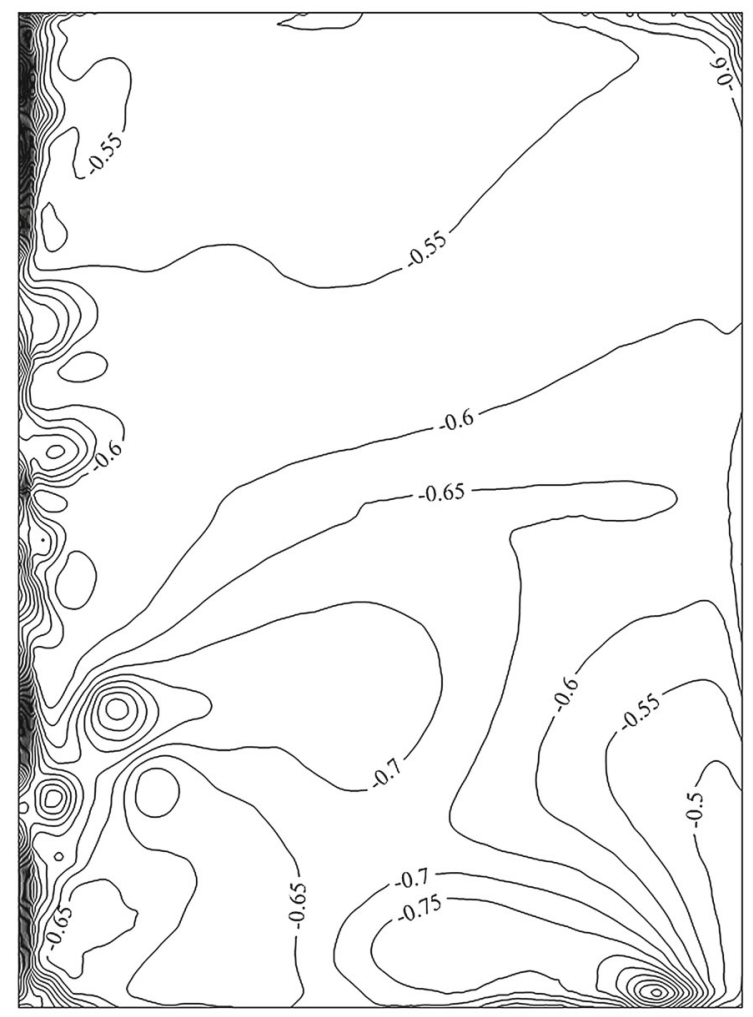

(c)

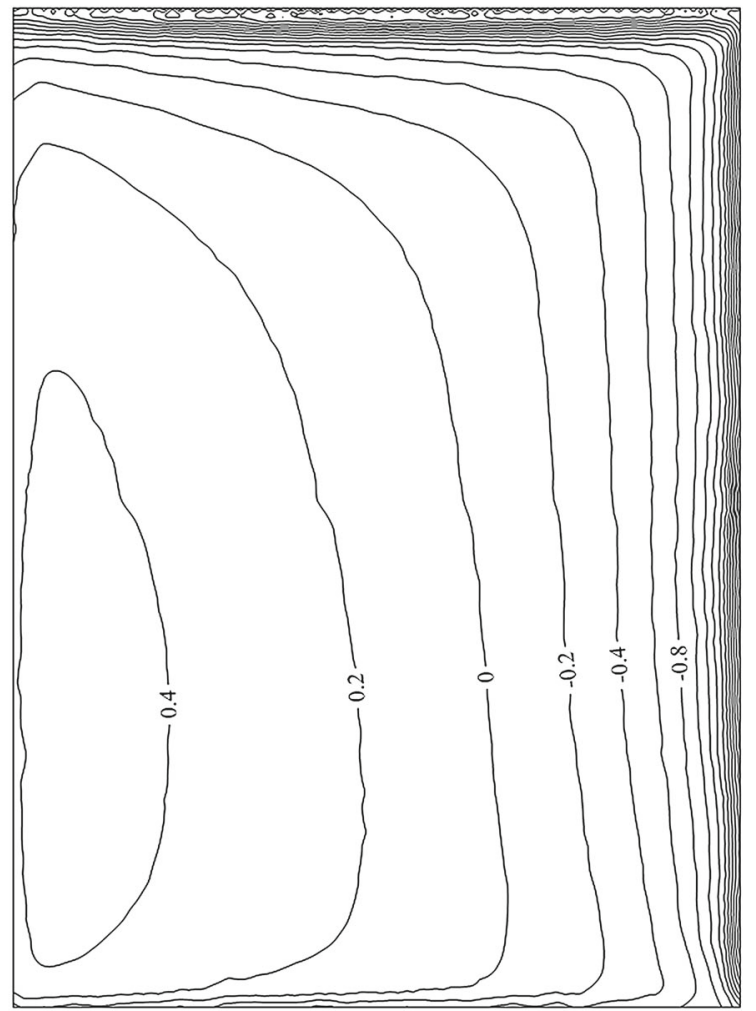

(b)

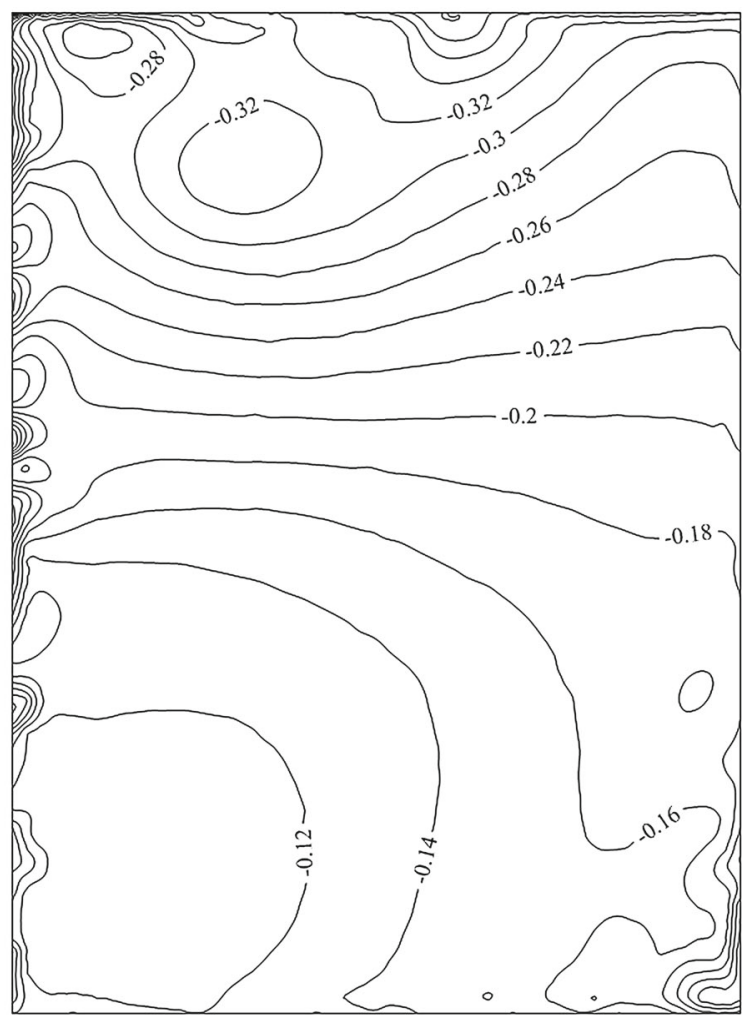

(d)

Fig. 6 Variations in coefficient of pressure $\left(C_{\mathrm{P}}\right)$ on the front face of the tractor-trailer unit at a relative flow angle $(\psi)$ of $\mathbf{a} 0^{\circ}, \mathbf{b} 45^{\circ}, \mathbf{c} 90^{\circ}, \mathbf{d ~} 150^{\circ}$, e $180^{\circ}$ 


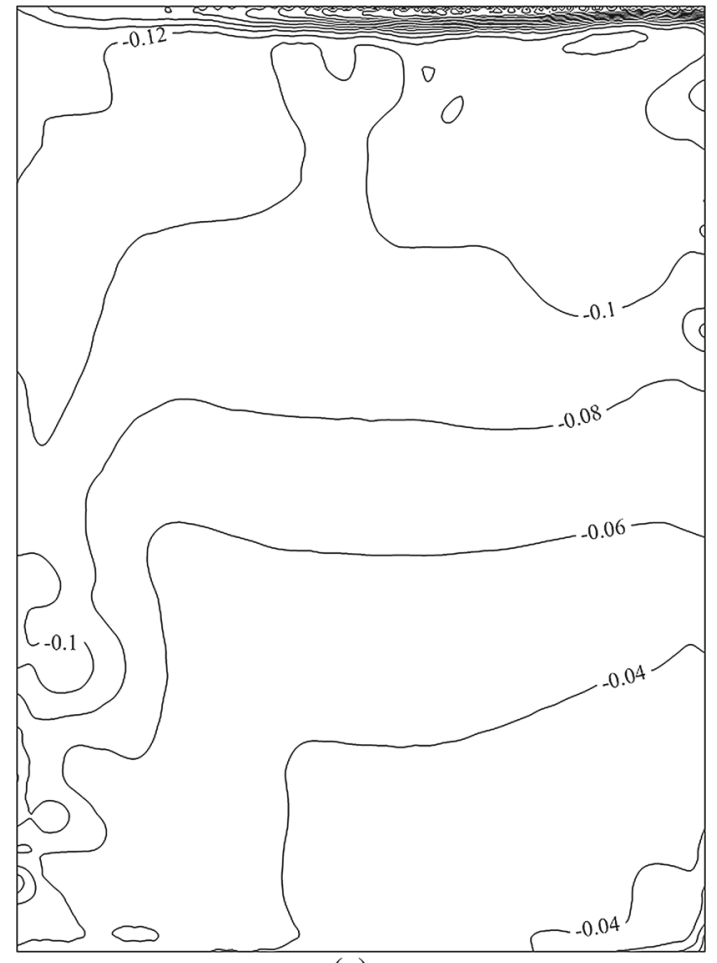

(e)

Fig. 6 continued

sure is seen to increase to $\Rightarrow-0.2$ near the back end of the tractor, where the flow gets re-attached to the surface of the tractor. Similarly, in the case of trailer, non-uniformity in pressure distribution is seen in the front half of this face. This non-uniformity in the pressure field can be attributed to the separation of the flow as it passes beyond the leading vertical edges of the trailer. The front end of the trailer region is seen to have a $C_{\mathrm{P}}$ value of -0.4 or less. The middle and the back end of the trailer depict $C_{\mathrm{P}}$ of -0.1 , which is substantially higher than at the front end of the trailer. This relatively higher-pressure region in the middle and the back of the trailer can be attributed to the re-attachment of the flow to the surface of the trailer.

In Fig. 7 b, where the relative flow angle changes to $45^{\circ}$, it is expected that as the flow is approaching the tractor-trailer model at an angle, the flow separation will take place from the edges of the right side surface predominantly. Hence, the lowest pressure points are observed to be on the periphery of the right surface of the tractor-trailer, as depicted in the figure. Moreover, as $\psi=45^{\circ}$, indicating that the flow is approaching equally from the side and the front of the vehicle, higher pressure is expected at the front section of the right surface, while the pressure is expected to decrease gradually towards the back end of the left surface. Combining these two observations, it can be clearly seen in Fig. 7b that a high value of $C_{\mathrm{P}}$ (around 0.9) exists near the leading edges of both the tractor and the trailer. This pressure is seen to gradually decrease to a very small value near the back end of the trailer $\left(C_{\mathrm{P}}=0\right.$ or less $)$.

Further increasing the yaw angle to $90^{\circ}$, Fig. $7 \mathrm{c}$ depicts that there is a symmetrical distribution of pressure on the entire right face of the vehicle, as expected, as the flow is now approaching the vehicle totally from its side; hence, the separation is only from the peripheral edges of the right surface. The pressure is highest in the centre of the right surface, while it decreases outwards (towards the peripheral edges). Further increase in the yaw angle to $150^{\circ}$ (in Fig. 7d) is expected to display qualitatively similar but opposite (in direction) pressure distribution to what has already been noticed in case of $\psi=45^{\circ}$. Hence, it can be clearly seen that the pressure is decreasing from the back of the trailer to the front of the tractor $\left(C_{\mathrm{P}}\right.$ from 0.45 at the back to -0.2 at the front). The same is the case of $\psi=180^{\circ}$, which is opposite to the case where $\psi=0^{\circ}$, as shown in Fig. 7e, as the flow is approaching the vehicle from its back, and that the flow separation is now taking place from the edges of the rear face of the trailer.

\subsection{Pressure Distribution on the Rear Face of the Trailer}

Figure 8 depicts the distribution of coefficient of pressure $\left(C_{\mathrm{P}}\right)$ on the rear face of the trailer at various relative flow angles considered in the present study. Figure 8a corresponds to $\psi=0^{\circ}$, where the flow is head-on to the tractor's frontal face. At this particular flow angle, the contribution of the rear surface of the trailer towards the aerodynamic drag force comes because of negative pressure, as the flow is not approaching the rear surface of the trailer directly. It can also be seen that the pressure distribution is highly non-uniform, where the average $C_{\mathrm{P}}$ has been measured to be -0.15 . Increasing the angle of attack to $45^{\circ}$, in Fig. 8 b, it can be seen that as the flow is now approaching from the right side in the figure, the flow separation is taking place at the right peripheral edge of the trailer's rear face. The average pressure on the surface is still low $\left(C_{\mathrm{P}}=-0.57\right)$. Further increase in the yaw angle to $90^{\circ}$, as seen in Fig. $8 \mathrm{c}$, it can be inferred that the flow separation on the right edge of the trailer's rear surface increases, resulting in further decrease in the pressure on the leading edge $\left(C_{\mathrm{P}}=-0.4\right.$ for $\psi=45^{\circ}$ to $C_{\mathrm{P}}=-0.75$ for $\psi=90^{\circ}$ ).

As the yaw angle increases to $150^{\circ}$, as in Fig. 8d, it can be seen that the flow is now directly approaching the surface from the right hand side in the figure, at an angle. As expected, the pressure is higher on the right hand side of the surface (where the flow contacts the surface), while it decreases (accelerates) towards the left hand side of the surface. The pressure distribution is quite uniform, and the overall pressure on the rear surface of the trailer has increased substantially. Figure 8e depicts the case where $\psi=180^{\circ}$, indicating head-on wind to the rear surface of the trailer. The 


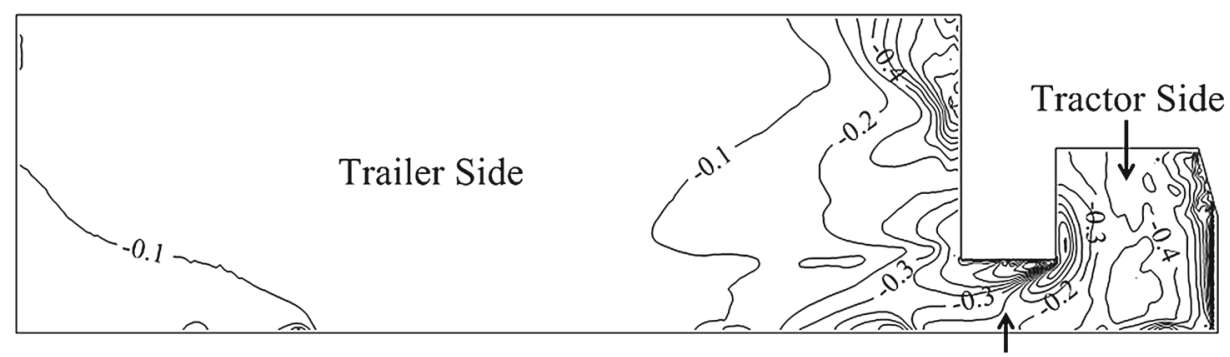

(a)

Bridge

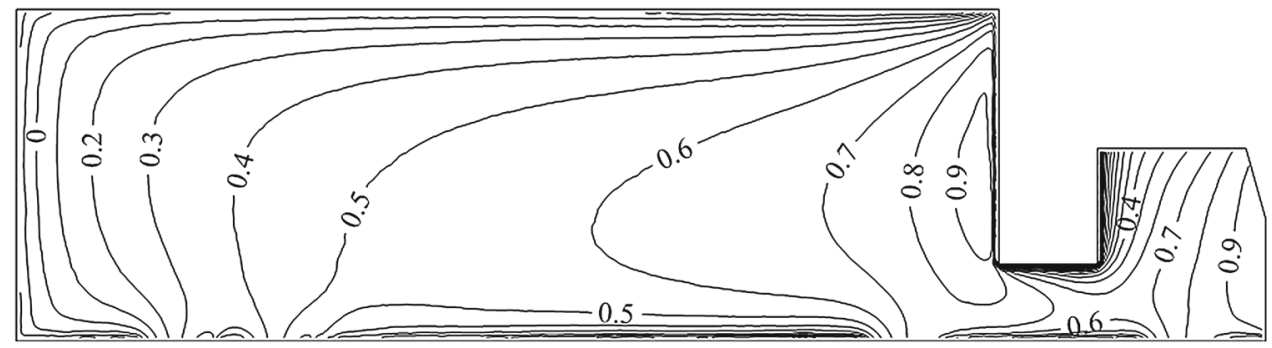

(b)

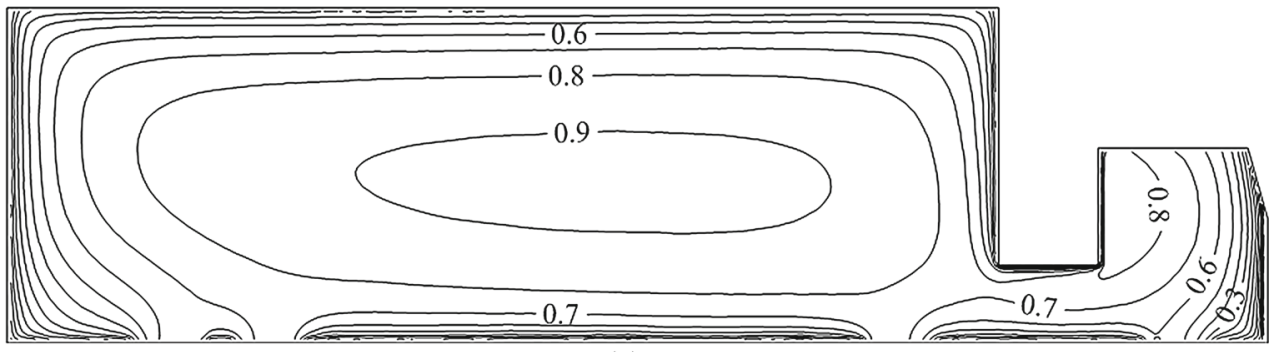

(c)

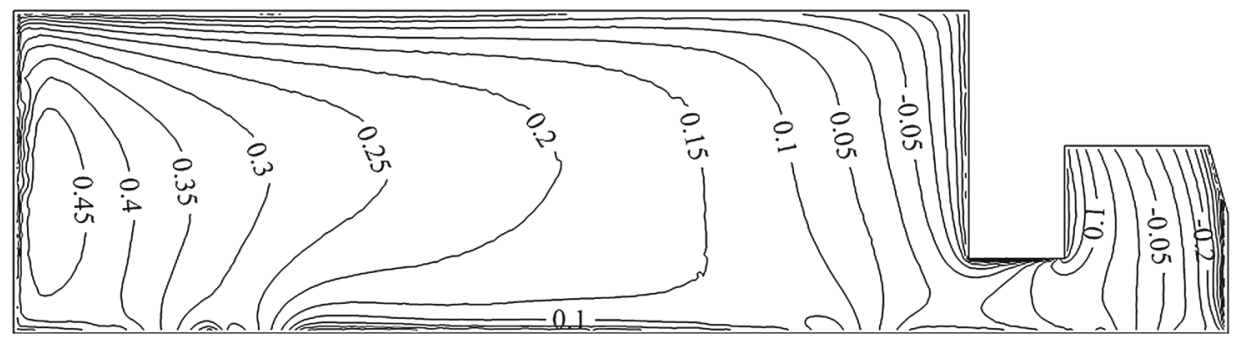

(d)

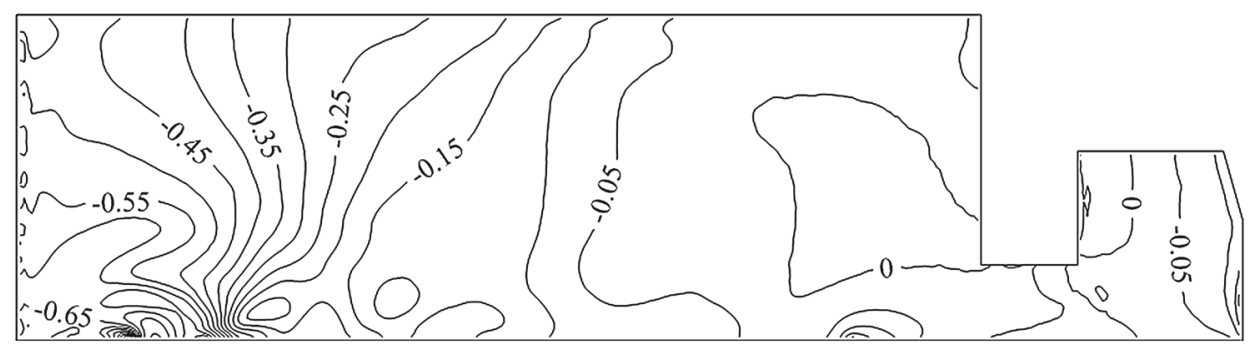

(e)

Fig. 7 Variations in coefficient of pressure $\left(C_{\mathrm{P}}\right)$ on the right face of the tractor-trailer unit at a relative flow angle $(\psi)$ of $\mathbf{a} 0^{\circ}, \mathbf{b} 45^{\circ}, \mathbf{c} 90^{\circ}, \mathbf{d} 150^{\circ}$, e $180^{\circ}$ 
Fig. 8 Variations in coefficient of pressure $\left(C_{\mathrm{P}}\right)$ on the rear face of the tractor-trailer unit at a relative flow angle $(\psi)$ of $\mathbf{a}$ $0^{\circ}, \mathbf{b} 45^{\circ}, \mathbf{c} 90^{\circ}, \mathbf{d} 150^{\circ}$, e $180^{\circ}$

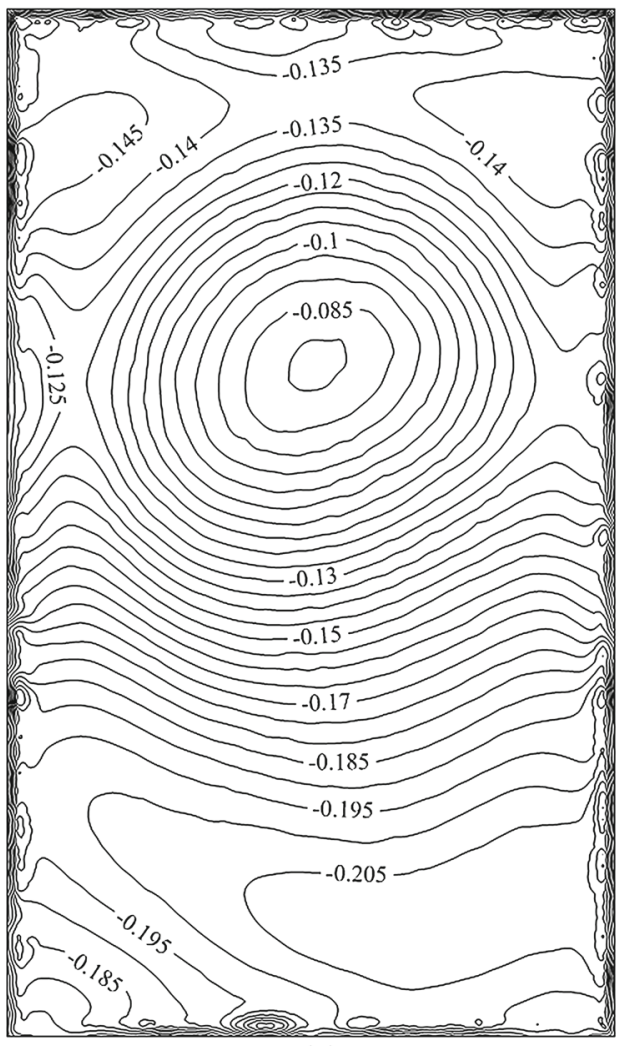

(a)

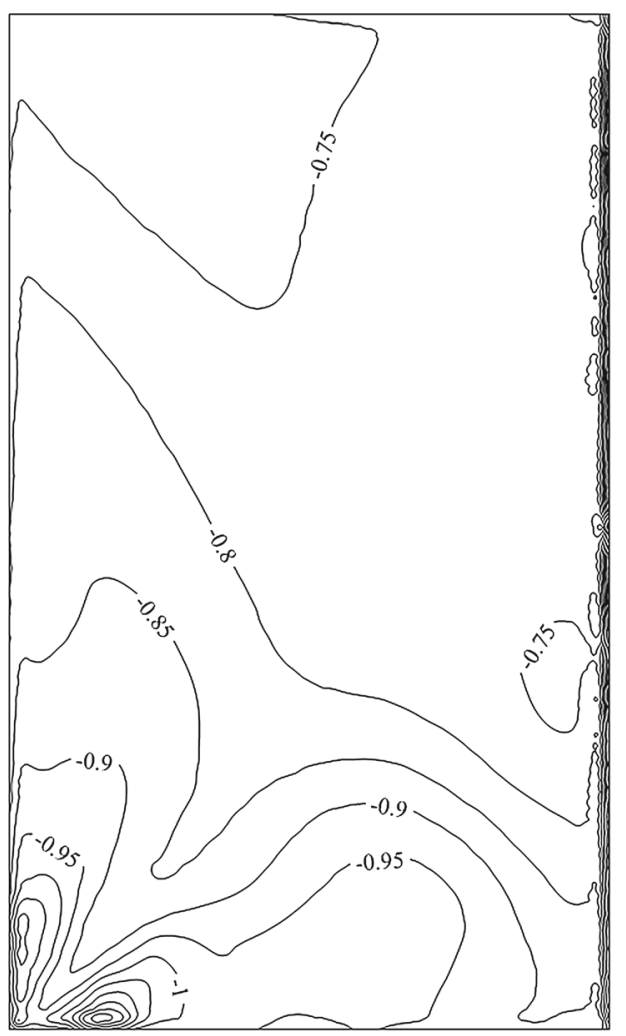

(c)

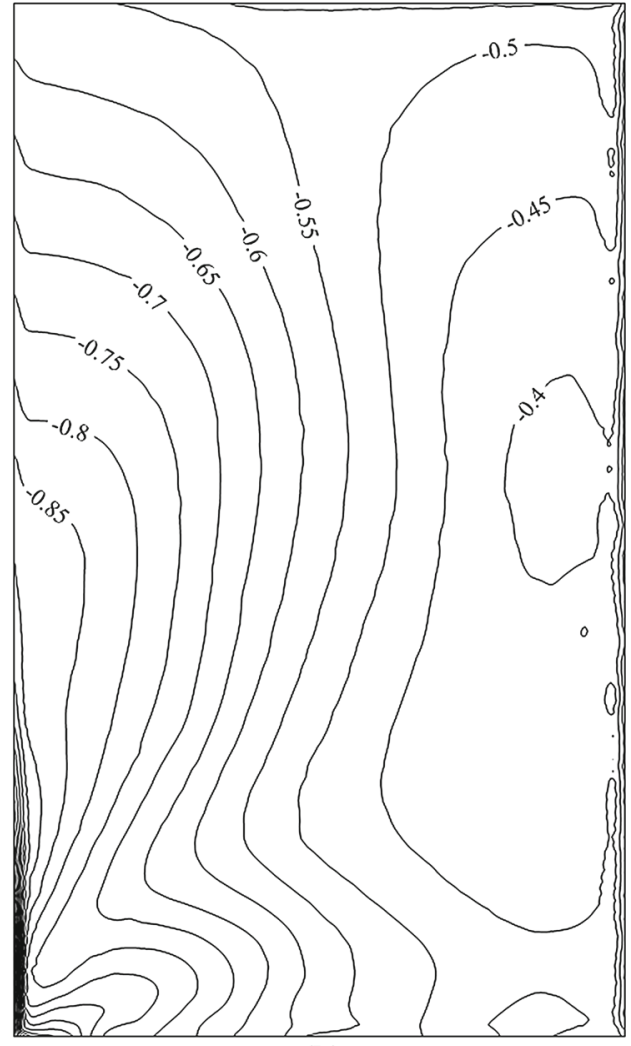

(b)

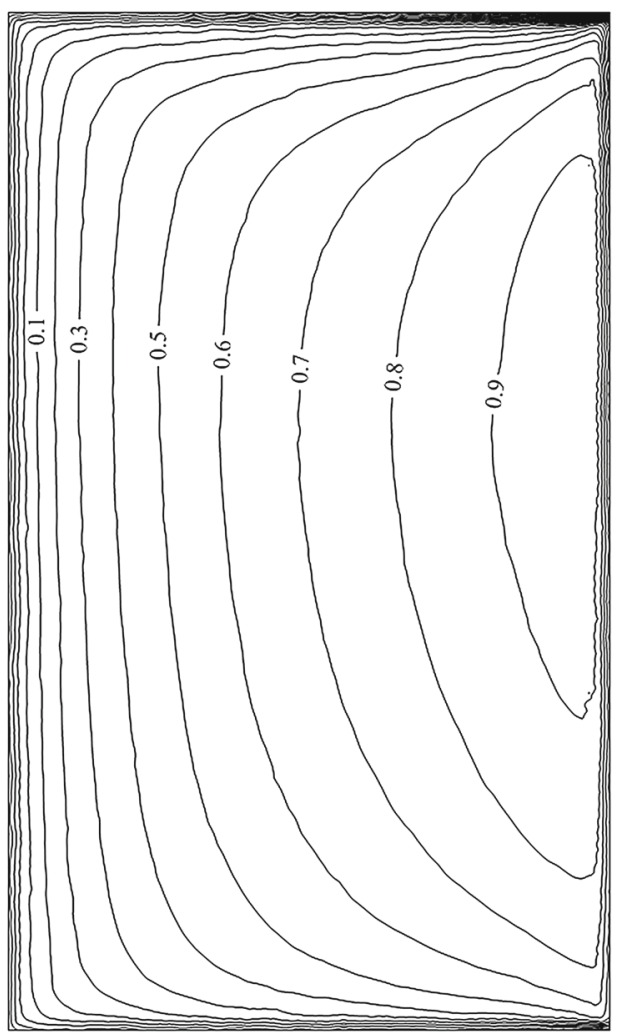

(d) 


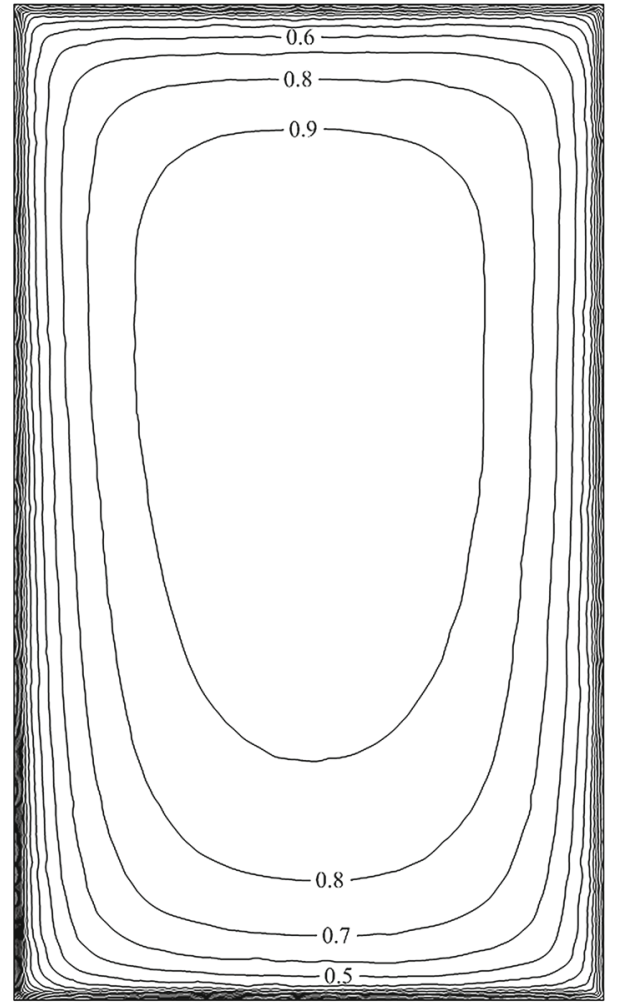

(e)

Fig. 8 continued

flow gets separated from the peripheral edges of the surface. The pressure is highest in the centre of the surface, gradually decreasing while going towards the edges of the surface.

\section{Variations in the Aerodynamic Forces acting on the Tractor-trailer Unit}

It has been noticed in the aerodynamic analysis of tractortrailer units that the pressure distribution on the vehicle is influenced by the relative flow angle. Such a variation in the pressure distribution is expected to influence the aerodynamic forces acting on the vehicle. Hence, Fig. 9 depicts the variations in the aerodynamic forces acting on the vehicle at various flow angles, as predicted by CFD simulations. It can be seen that the drag force is positive for flow angles up to a value of $60^{\circ}$, and negative for higher angles. The highest positive value of the drag force has been recorded to be $5124 \mathrm{~N}$, which occurs when the flow is at $15^{\circ}$ angle. Similarly, the highest negative value of the drag force is recorded to be $-1126 \mathrm{~N}$, when the flow angle is at $150^{\circ}$.

The lift force is found to increase to $6737 \mathrm{~N}$ from $\psi=0^{\circ}$ to $30^{\circ}$ and then decrease to $-1168 \mathrm{~N}$ at $\psi=90^{\circ}$. Further increasing the yaw angles increases the lift force again up to $\psi=150^{\circ}$, after which, it starts to decrease again. Hence,

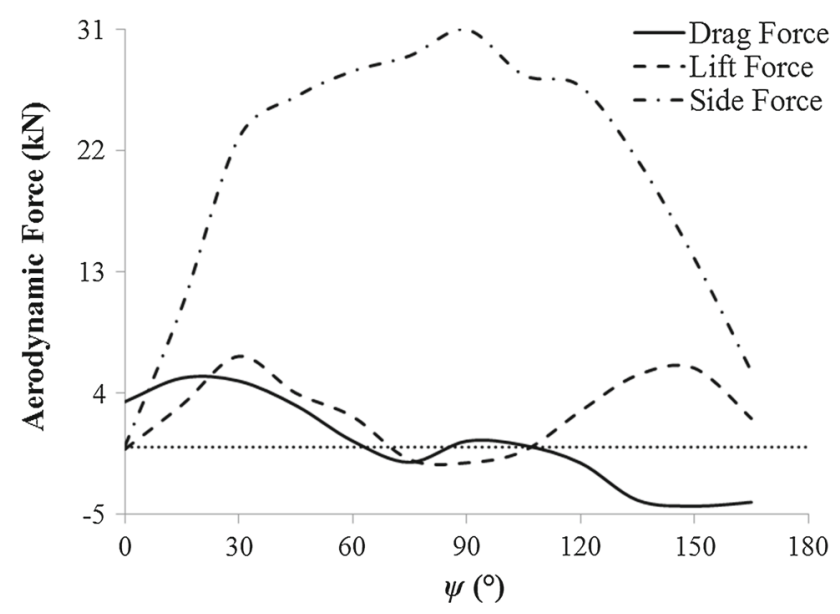

Fig. 9 Variations in the aerodynamic forces acting on tractor-trailer unit at various relative flow angles

the trend in the lift force is also symmetrical about the $90^{\circ}$ yaw angle. The side force is seen to be positive throughout the range of flow angles investigated. The side force is also symmetrical about $90^{\circ}$ yaw angle. It is seen to be very low when the flow is parallel to the vehicle axis in either direction. A remarkable increase is observed in the side force even at small deviation from this parallel position. It is seen to rise to $10,410 \mathrm{~N}$ when the flow angle increases from $0^{\circ}$ to $15^{\circ}$. Since the side force is the component of the aerodynamic force vector which acts along the $\mathrm{z}$ axis of the vehicle, it is seen to be highest at $90^{\circ}(30,974 \mathrm{~N})$, when the flow is approaching the vehicle from its side. Moreover, variations in the side force have been measured to be relatively small for the range of flow angles between $30^{\circ}$ and $150^{\circ}$.

Quantitative analysis on the aerodynamic drag force acting on the various surfaces of the tractor-trailer unit, for yaw angles of $0^{\circ}$ and $45^{\circ}$ is presented in Table 3 . The two components of force, i.e. the pressure component and the viscous component, have also been recorded to critically analyse the aerodynamic behaviour of the tractor-trailer unit under varying yaw angles. The data collected indicate that at $0^{\circ}$ yaw angle, the front surface of the tractor contributes to the total drag by $36.4 \%$, whereas the front surface of the trailer contributes $46 \%$. The rear surfaces of both the tractor and the trailer contribute 4.2 and $20.5 \%$, respectively. However, at $45^{\circ}$ yaw angle, the rear surfaces of the tractor and the trailer contribute 39.5 and $53.8 \%$, respectively. It is of particular interest that the drag contributions of the front surfaces of the tractor and the trailer decrease to 0.91 and $21.1 \%$, respectively, at yaw angle of $45^{\circ}$. The drag force acting on the rear surfaces of the tractor-trailer unit has been calculated as a positive force because the drag force has been calculated along the direction of travel.

It can be concluded from the above discussions that the relative flow angle has a significant impact on the local flow 
Table 3 Drag force contributions from various surfaces of the tractor-trailer unit at different flow angles

\begin{tabular}{|c|c|c|c|c|c|c|}
\hline \multirow[t]{2}{*}{ Surface } & \multicolumn{3}{|c|}{ Yaw angle $0^{\circ}$} & \multicolumn{3}{|c|}{ Yaw angle $45^{\circ}$} \\
\hline & $\begin{array}{l}\text { Pressure } \\
(N)\end{array}$ & $\begin{array}{l}\text { Viscous } \\
(N)\end{array}$ & $\begin{array}{l}\text { Total } \\
(N)\end{array}$ & $\begin{array}{l}\text { Pressure } \\
(N)\end{array}$ & $\begin{array}{l}\text { Viscous } \\
(N)\end{array}$ & $\begin{array}{l}\text { Total } \\
(N)\end{array}$ \\
\hline Tractor front & +1226.2 & +1.6 & +1227.8 & -29.07 & +0.8 & -28.3 \\
\hline Tractor rear & +141.0 & 0.0 & +141.0 & +1220.8 & 0.0 & +1220.8 \\
\hline Trailer front & +1550.9 & 0.0 & +1550.9 & -652.4 & 0.0 & -652.4 \\
\hline Trailer rear & +692.0 & 0.0 & +692.0 & +1662.8 & 0.0 & +1662.8 \\
\hline
\end{tabular}

distribution, as well as the aerodynamic forces acting on the vehicle. Accurate prediction of these forces analytically requires a reliable methodology to quantify and predict the corresponding aerodynamic coefficients. This was attempted by Baker [15] for large bus bodies. It is thus required to establish a relationship between the relative flow angle, vehicle's dimensions and the aerodynamic coefficients for tractortrailers which are very different from large rigid bus structure. Hence, further investigations are based on characterising the aerodynamic forces by the overall dimensions of the vehicle, i.e. length $(l)$, width $(w)$, height $(h)$ and the yaw angle $(\psi)$.

\section{Novel Characterisation Methodology for the Aerodynamic Coefficients on a Tractor-Trailer Unit}

The aerodynamic forces and moments acting on a vehicle are influenced by the fluid (air) density, size and shape of the vehicle, characteristic area (usually frontal), relative flow velocity magnitude, etc. Frontal area is used as the characteristic area in the developed relationships as this is the area that corresponds to the projection of the vehicle's normal to the flow, when the relative flow angle is low $\left(<8^{\circ}\right)$ [2]. An attempt has been made by Baker [15] to expand the scope of these aerodynamic equations to embrace the effects of relative flow angles, so that the aerodynamic effects can be predicted more accurately for large bus bodies. The coefficients used in Eqs. (4)-(6) correspond to atlantean bus geometry. It is expected that these coefficients will be considerably different for tractor-trailers because of considerable difference in geometry and the corresponding flow fields. The flow field corresponding to different sized trailers is also expected to be different; hence, it is expected that these coefficients may be a function of size parameters of the trailer. In particular, the size of the vehicle is of significant importance at high yaw angle, which needs to be included in the analysis. This presents an opportunity to expand the scope of these equations to encompass both the flow angle and the vehicle dimensions.

\subsection{Effect of Vehicle's Size on the Aerodynamic Coefficients}

Before developing a characterisation methodology for the prediction of aerodynamic coefficients on a tractor-trailer unit of various sizes, operating in different flow conditions, it is prudent to first analyse the effect of the vehicle size on these coefficients. Figures 10 and 11 depict the variation in the drag $\left(C_{\mathrm{D}}\right)$, side $\left(C_{\mathrm{S}}\right)$ and the lift $\left(C_{\mathrm{L}}\right)$ coefficients at various yaw angles $(\psi)$ for different heights and lengths of the vehicle. Figure 10 depicts the variations in the aerodynamic coefficients for a $16.28 \mathrm{~m}$ long tractor-trailer unit, having heights of 4.4, 4.6 and $4.8 \mathrm{~m}$, respectively. It can be seen that as the yaw angle of the vehicle increases, the drag coefficient increases, up to a yaw angle of $15^{\circ}$. From $\psi=15^{\circ}$ to $75^{\circ}$, the drag coefficient can be seen to decrease, while it increases again at $\psi=90^{\circ}$. This trend is in-line with the findings of Coleman and Baker [18]. It can be further observed that as the height of the vehicle increases from 4.4 to $4.6 \mathrm{~m}$, at lower yaw angles, there is negligible effect on the drag coefficient of the vehicle. However, at $\psi=45^{\circ}$ and higher, the drag coefficient for $4.6 \mathrm{~m}$ high vehicle reduces significantly $(23.8 \%)$ as compared to the vehicle with height $4.4 \mathrm{~m}$. As the height of the vehicle further increases to $4.8 \mathrm{~m}$, from $\psi=0^{\circ}$ to $45^{\circ}$, the drag coefficient is higher for $4.8-\mathrm{m}$-high vehicle $(10.7 \%)$, while at higher yaw angles, there is negligible difference in the drag coefficients between 4.4- and 4.8-m-high vehicles.

In case of side coefficient (Fig. 10b), it can be seen that as the yaw angle increases, the side coefficient also increases, up to $\psi=45^{\circ}$, which corresponds to the peak of the side coefficient. Further increase in the yaw angle to $\psi=60^{\circ}$ decreases the side coefficient; however, further increase in the yaw angle gradually increases the side coefficient of the vehicle. These trends are in-line with the coefficient of pressure being observed in Fig. 6b, c, and with Coleman and Baker [18]. It can be further seen in the figure that as the height of the vehicle increases, the side coefficient also increases (for most part of the operating range). On average, a vehicle with $4.6 \mathrm{~m}$ height depicts $8.5 \%$ higher side coefficient, while a vehicle with $4.8 \mathrm{~m}$ height shows $11.4 \%$ higher side coeffi- 

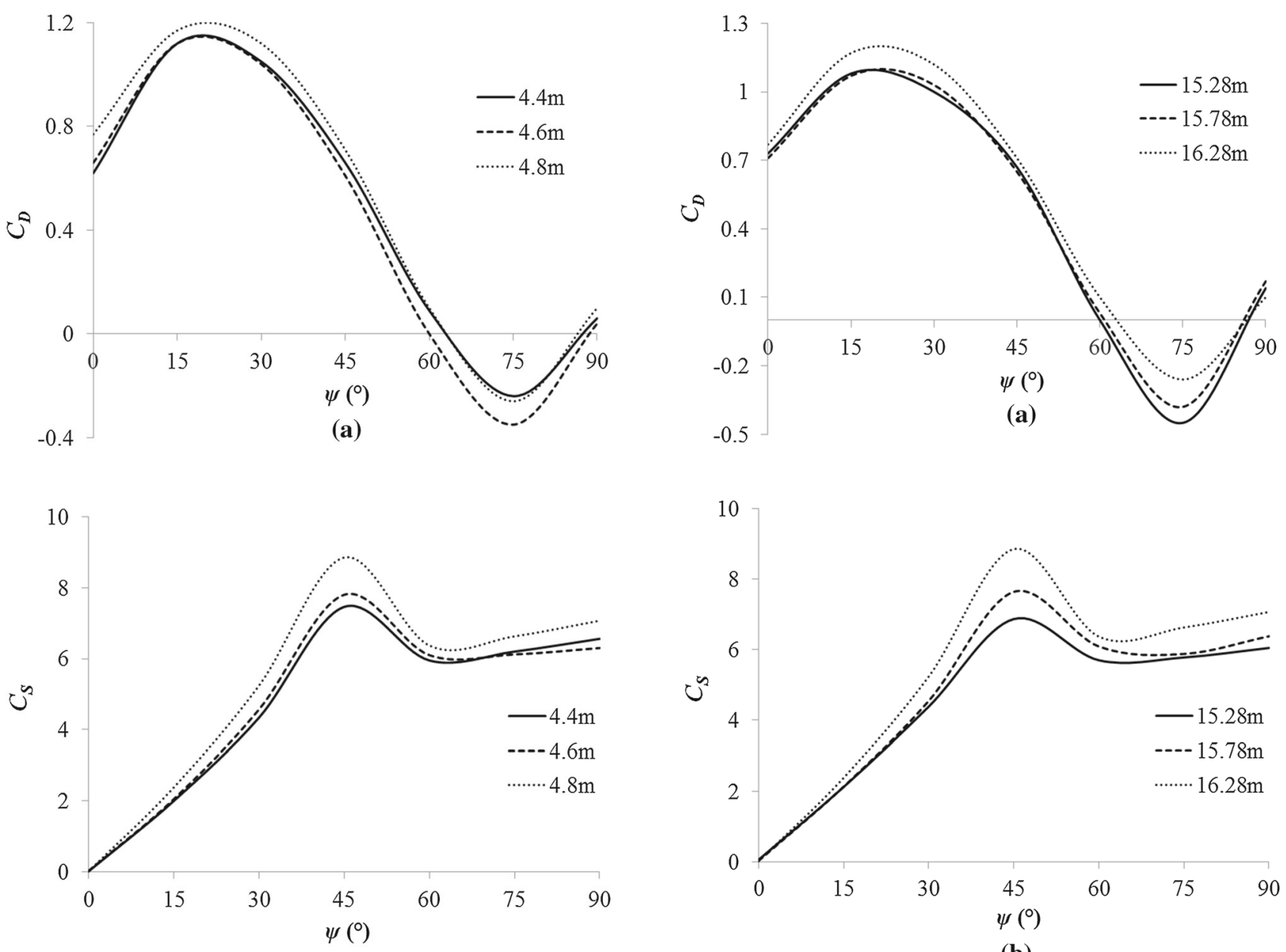

(b)
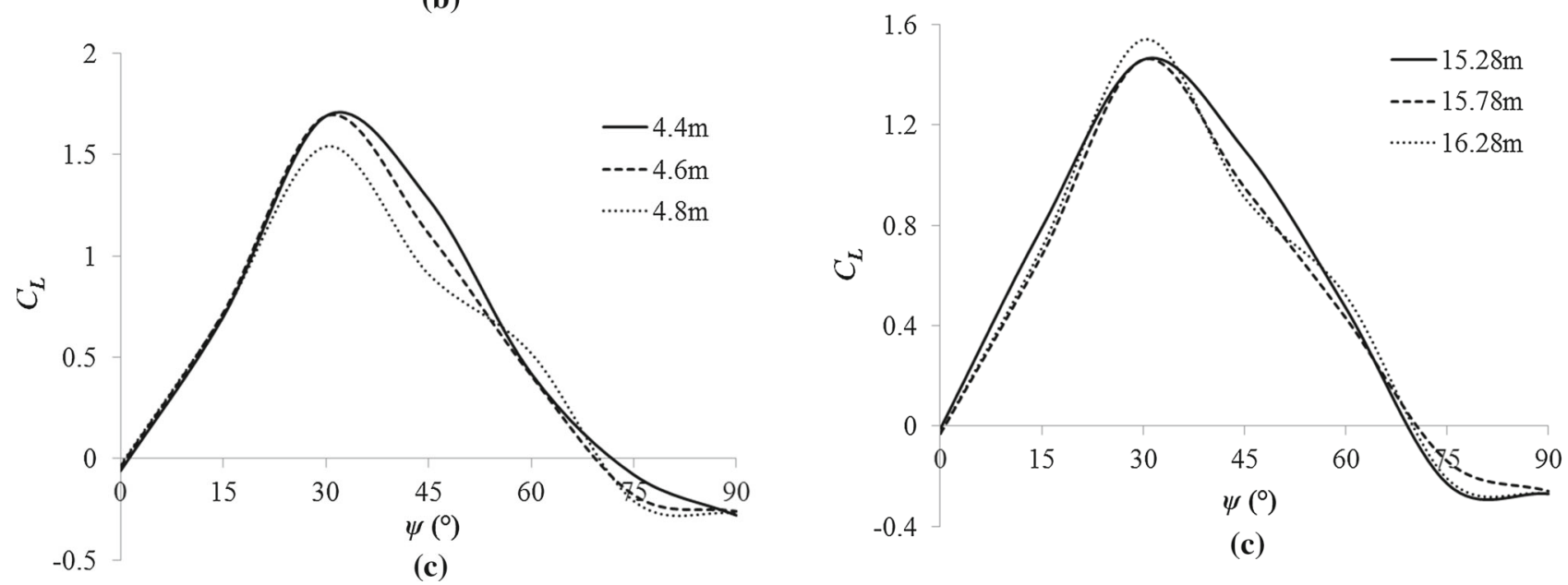

(c)

Fig. 10 Variations in aerodynamic coefficients at various flow angles $(\psi)$ for 16.28-m-long tractor-trailer of different heights, a drag coefficient $\left(C_{\mathrm{D}}\right)$, b side coefficient $\left(C_{\mathrm{S}}\right), \mathbf{c}$ lift coefficient $\left(C_{\mathrm{L}}\right)$

cient as compared to 4.4-m-high vehicle. The variations in the lift coefficient are qualitatively similar to the variations in the drag coefficient, apart from the observation that the highest lift coefficient is observed to be at $\psi=30^{\circ}$, instead

Fig. 11 Variations in aerodynamic coefficients at various flow angles $(\psi)$ for 4.8-m-high tractor-trailer of different heights, a drag coefficient $\left(C_{\mathrm{D}}\right), \mathbf{b}$ side coefficient $\left(C_{\mathrm{S}}\right), \mathbf{c}$ lift coefficient $\left(C_{\mathrm{L}}\right)$

of $15^{\circ}$. Moreover, from $\psi=75^{\circ}$ to $90^{\circ}$, further decrease in the lift coefficient can be noticed. As the height of the vehicle increases, at higher yaw angles $\left(<15^{\circ}\right)$, the lift coefficient of the vehicle decreases. On average, a 4.6-m-high vehicle depicts a $10.2 \%$ reduction in the lift coefficient, whereas a 
4.8-m-high vehicle shows $13.8 \%$ reduction, as compared to a 4.4-m-high vehicle.

Figure 11 depicts the variations in the aerodynamic coefficients for a 4.8-m-high tractor-trailer unit, having lengths of $15.28,15.78$ and $16.28 \mathrm{~m}$, respectively. It can be seen in Fig. 11a that the variations in the drag coefficient, as the length of the vehicle varies, are similar to the one observed in case of the effect of vehicle height on $C_{\mathrm{D}}$, i.e. as the length of the vehicle increases, the drag coefficient also increases. However, at higher yaw angles, this trend is reversed, i.e. as the length of the vehicle increases, the drag coefficient decreases. Hence, the drag coefficient of 16.28-m-long vehicle is, on average, $7.9 \%$ higher than a vehicle of $15.28 \mathrm{~m}$ length, from $\psi=0^{\circ}$ to $45^{\circ}$. From $\psi=45^{\circ}$ to $90^{\circ}$, however, there is $16.2 \%$ reduction in the drag coefficient for $16.28-\mathrm{m}$ long vehicle.

It can be seen in Fig. $11 \mathrm{~b}$ that the variations in the side coefficient, as the length of the vehicle varies, are comparable to the variations observed in case of the effect of the vehicle height, with similar trends. Hence, 15.78- and 16.28-m-long vehicles depict 4.9 and $17.3 \%$ increases in the side coefficient, as compared to a vehicle of $15.28 \mathrm{~m}$ length. Moreover, as the length of the vehicle increases, the lift coefficient (shown in Fig. 11c), on average, decreases. 15.78and 16.28-m-long vehicles depict 13.2 and 3.3\% reduction in the side coefficient, as compared to a vehicle of $15.28 \mathrm{~m}$ length.

\subsection{Development of Semi-empirical Prediction Models for the Aerodynamic Coefficients of a Tractor-Trailer Unit}

As discussed earlier, the aerodynamic coefficients are influenced by the vehicle's dimension, as well as the relative flow angle. The values of the aerodynamic coefficients obtained under known conditions, from CFD predictions, have been used to develop novel semi-empirical correlations between the dimensions of the vehicle, flow angle, and the aerodynamic coefficient, where these correlations are similar to Coleman and Baker [18], but for a flexible tractor-trailer unit rather than a rigid bus. Based on its behaviour, drag coefficient $\left(C_{\mathrm{D}}\right)$ of a tractor-trailer unit can be characterised by its length $(l)$ and height $(h)$. These dimensions have been converted to non-dimensional form using the vehicle's width $(w)$, as discussed previously in Table 1 . As the variations in the aerodynamic coefficients have been shown earlier to be nonlinear in nature, the generalised reduced gradient (GRG) nonlinear optimisation model has been incorporated to optimise the coefficients in Eqs. (4-6) for a tractor-trailer unit [42]. Moreover, an advanced statistical process, known as multiple regression analysis, has been used on all the CFD results obtained to estimate the relationship between tractor-trailer's geometrical characteristics and its aerody- namic coefficients. The relationship for the drag coefficient can be represented as:

$C_{\mathrm{D}}=C_{\mathrm{Do}}(1+A \cdot \sin (B \cdot \psi))$

here $C_{\mathrm{Do}}$ is the drag coefficient corresponding to zero degree flow angle, whereas $A$ and $B$ are the coefficients that are expected to depend on the flow angle and vehicle's geometrical parameters. It must be mentioned that for a tractor-trailer unit:

$A=\left(\frac{8.24}{\left(\frac{l}{w}\right)^{0.72}\left(\frac{h}{w}\right)^{0.67}}\right)$

and

$B=\left(\frac{6.07 \frac{h}{w}^{0.085}}{\left(\frac{l}{w}\right)^{0.31}}\right)$

Hence, the drag coefficient equation can be written as:

$C_{\mathrm{D}}=0.55\left(1+\left(\frac{8.24}{\left(\frac{l}{w}\right)^{0.72}\left(\frac{h}{w}\right)^{0.67}}\right) \cdot \sin \left(\left(\frac{6.07 \frac{h^{0}}{w}}{\left(\frac{l}{w}\right)^{0.31}}\right) \cdot \psi\right)\right)$

Similarly, the side coefficient $\left(C_{\mathrm{S}}\right)$ can be represented as:

$C_{\mathrm{S}}=C \cdot \psi^{D}$

where

$C=\left(0.1\left(\frac{l}{w}\right)^{1.93}\left(\frac{h}{w}\right)^{0.79}\right)$

and

$D=\left(\frac{1.2 \frac{l}{w}^{0.04}}{\left(\frac{h}{w}\right)^{1.19}}\right)$

Thus, the side coefficient equation can be written as:

$C_{\mathrm{S}}=\left(0.1\left(\frac{l}{w}\right)^{1.93}\left(\frac{h}{w}\right)^{0.79}\right) \cdot \psi\left(\frac{1.2\left(\frac{l}{w}\right)^{0.04}}{\left(\frac{h}{w}\right)^{1.19}}\right)$

Finally, the lift coefficient $\left(C_{\mathrm{L}}\right)$ has been characterised by vehicle's dimensions and flow angle as:

$C_{\mathrm{L}}=E \cdot \sin (F \cdot \psi)$ 


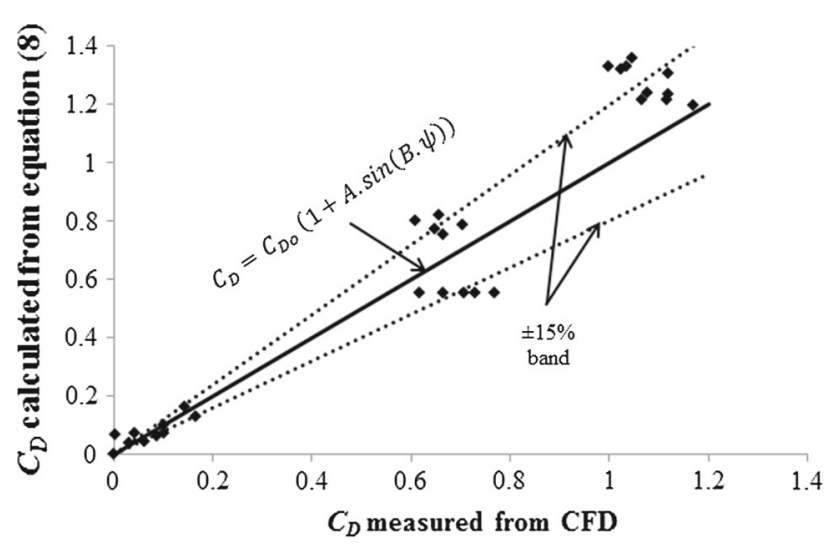

(a)

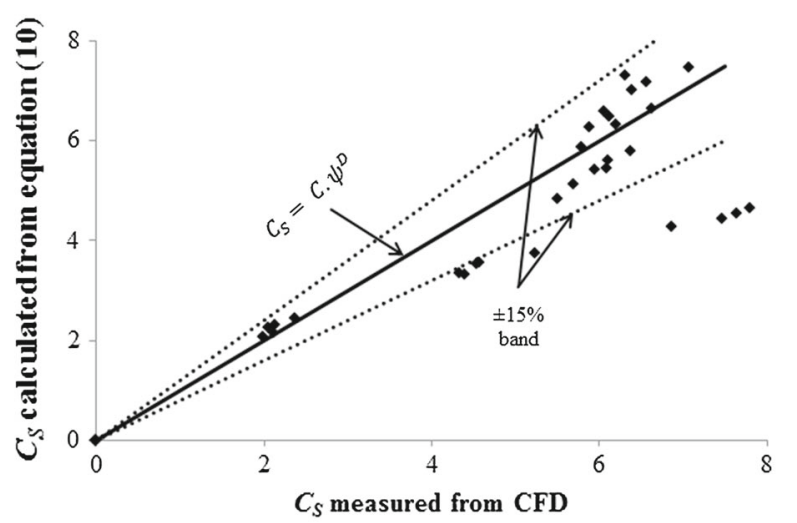

(b)

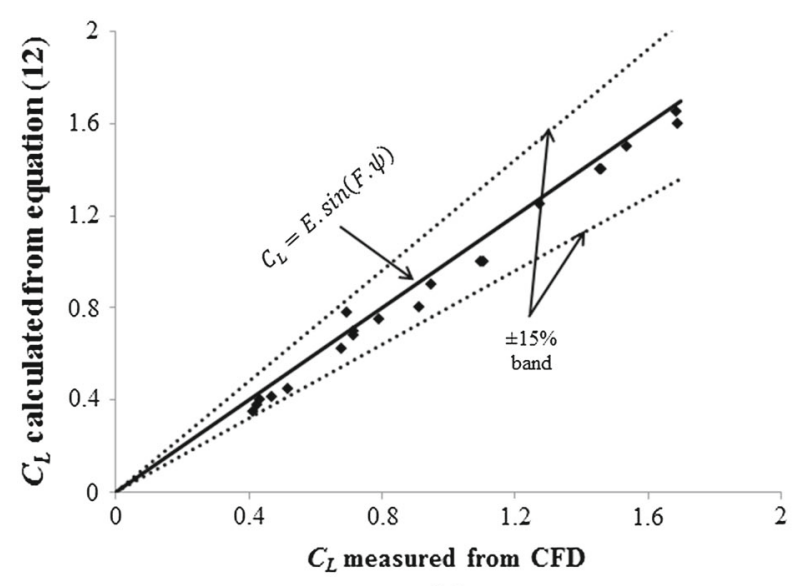

(c)

Fig. 12 Correlation between aerodynamic coefficients measured from CFD and calculated by the new methodology for various vehicle geometries and relative flow angles, a drag coefficient $\left(C_{\mathrm{D}}\right)$, b side coefficient $\left(C_{\mathrm{S}}\right), \mathbf{c}$ lift coefficient $\left(C_{\mathrm{L}}\right)$

where

$E=\left(\frac{0.89\left(\frac{l}{w}\right)^{0.28}}{\left(\frac{h}{w}\right)^{0.35}}\right)$ and

$F=\left(2.09\left(\frac{l}{w}\right)^{0.04}\left(\frac{h}{w}\right)^{0.57}\right)$

giving the final lift coefficient equation as:

$C_{\mathrm{L}}=\left(\frac{0.89\left(\frac{l}{w}\right)^{0.28}}{\left(\frac{h}{w}\right)^{0.35}}\right) \cdot \sin \left(\left(2.09\left(\frac{l}{w}\right)^{0.04}\left(\frac{h}{w}\right)^{0.57}\right) \cdot \psi\right)$

Figure 12 depicts the correlation between the CFD predicted values of the aerodynamic coefficients, and those obtained from Eqs. (11), (13) and (15). It can be clearly seen that the CFD predicted values agree reasonably well with those obtained from the semi-empirical equations. Standard error of estimate and the Chi-square have been calculated, and these are approximately $15 \%$ and 0.88 , respectively, indicating reasonably good accuracy levels. Hence, Eqs. (11), (13) and (15), developed for characterising the aerodynamic coefficients in terms of the vehicle's dimensions and the relative flow angle, are capable of predicting the aerodynamic coefficients for a tractor-trailer unit of various sizes for different flow conditions, with reasonable accuracy. This methodology allows for the effective use of CFD in the early design phases of tractor-trailer units.

In order to further validate the aerodynamic coefficients computed using Eqs. (11), (13) and (15), the flow around the baseline tractor-trailer unit has been numerically simulated for $\psi=10^{\circ}, 40^{\circ}$ and $70^{\circ}$. The numerically predicted aerodynamic coefficients have been recorded and then compared against the values computed from the equations developed for the same yaw angles. This comparison is summarised in Table 4. It can be clearly seen that the data generated on the additional points also match well with the equations developed.

Table 4 Comparison of numerically predicted aerodynamic coefficients on the baseline tractor-trailer unit against the equations developed

\begin{tabular}{lccc}
\hline Aerodynamic coefficient & $\psi=10^{\circ}$ & $\psi=40^{\circ}$ & $\psi=70^{\circ}$ \\
\hline$C_{\mathrm{D}}$ (CFD) & 1.11 & 0.98 & -0.20 \\
$C_{\mathrm{S}}$ (CFD) & 1.78 & 4.63 & 6.81 \\
$C_{\mathrm{L}}$ (CFD) & -0.027 & 0.60 & 1.62 \\
$C_{\mathrm{D}}$ (Eq. 11) & 1.02 & 1.01 & -0.21 \\
$C_{\mathrm{S}}$ (Eq. 13) & 1.89 & 4.49 & 6.37 \\
$C_{\mathrm{L}}$ (Eq. 15) & -0.03 & 0.68 & 1.50 \\
$\%$ diff. in $C_{\mathrm{D}}$ & 8.7 & -3.1 & -5.3 \\
$\%$ diff. in $C_{\mathrm{S}}$ & -5.8 & 3.1 & 6.9 \\
$\%$ diff. in $C_{\mathrm{L}}$ & -6.9 & -11.8 & 8.0 \\
\hline
\end{tabular}




\section{Conclusions}

The prediction of aerodynamic forces and moments is necessary to characterise operational and performance characteristics of tractor-trailer combinations. Use of existing relationships for broadly similar vehicles for computing aerodynamic coefficients offers only a rough estimate of these coefficients, which become highly unreliable in conditions when the angle of attack of the flow is high $\left(>8^{\circ}\right)$. The limitation of the standard methodology to accurately predict the aerodynamic forces accurately for large angles of attack has been discussed in detail in the present study. The behaviour of flow around a tractor-trailer unit, and the consequent pressure distribution in the vicinity of the unit, have been analysed for a range of flow angles between $0^{\circ}$ and $180^{\circ}$. It has been observed that due to flow separation on various edges of the tractor-trailer unit at different flow angles, the pressure distribution observed on the key surfaces of the unit is highly non-uniform. Influence of flow angle on the three aerodynamic coefficients has been analysed. It has been observed that at a flow angle of $60^{\circ}$, drag coefficient is seen to reduce by $91 \%$ on average as compared to its peak value at $15^{\circ}$.

It has also been shown how the inherently simple shapes of commercial vehicles allow the use of major geometrical dimensions (length, width and height) of these vehicles to be used to estimate their aerodynamic performance. It has been observed that for different sized tractor-trailer units, as the flow angle increases, all the aerodynamic forces acting on them also increase up to a certain flow angle, after which, reduction in both the drag and lift forces have been noticed, while the side force remains almost constant. Based on these results, a characterisation methodology has been developed to determine the aerodynamic coefficients under a wide range of geometrical and flow conditions. The inclusion of major dimensions of the vehicles in the proposed model enables this method to encompass the key vehicle dimensions, making this method more robust.

Open Access This article is distributed under the terms of the Creative Commons Attribution 4.0 International License (http://creativecomm ons.org/licenses/by/4.0/), which permits unrestricted use, distribution, and reproduction in any medium, provided you give appropriate credit to the original author(s) and the source, provide a link to the Creative Commons license, and indicate if changes were made.

\section{References}

1. Baker, C.J.; Reynolds, S.: Wind-induced accidents of road vehicles. Accid. Anal. Prev. 24(6), 559-575 (1992)

2. Hucho, W.: Aerodynamics of Road Vehicles, 4th edn. Society of Automotive Engineers (SAE), New York (1998)

3. Asim, T.; Sendanayake, I.; Mishra, R.;, Zala, K.; Ubbi, K.: Effects of moving boundary layer control (MSBC) on the drag reduction in heavy commercial vehicles. In: 40th National Conference on Fluid Mechanics and Fluid Power, NIT Hamirpur, pp. 12-14, Paper No. 154 (Dec. 2013)

4. Malviya, V.U.: Effects of a novel aerodynamic intervention for heavy commercial vehicles on fuel saving and stability. Ph.D. Thesis, University of Huddersfield (2011)

5. Rose, M.J.: Commercial vehicle fuel economy-the correlation between aerodynamic drag and fuel consumption of a typical tractor. Wind Eng. Ind. Aerodyn. 9(1-2), 89-100 (1981)

6. Calkins, D.E.; Su, W.; Chan, W.T.: A design rule-based tool for automobile systems design. SAE Technical Paper 980397 (1998)

7. Singh, R.: Automated aerodynamic design optimization process for automotive vehicle. SAE Technical Paper 2003-01-0993 (2003)

8. Malviya, V.U.; Mishra, R.; Fieldhouse, J.: Enhanced analytical vehicle stability model. In: 12th EAEC European Automotive Congress, Bratislava (29 June-1 July 2009)

9. Malviya, V.U.; Mishra, R.: Development of an analytical multivariable steady-state vehicle stability model for heavy road vehicles. Appl. Math. Model. 38(19-20), 4756-4777 (2014)

10. Malviya, V.U.; Mishra, R.; Fieldhouse, J.: CFD investigation of a novel fuel-saving device for articulated tractor-trailer combinations. Eng. Appl. Comput. Fluid Mech. 3(4), 587-607 (2009)

11. Berta, C.; Tacca, T.; Zucchelli, A.: Aerodynamic study on vehicle shape with the panel method: an effort to calculate the influence of shape characteristics on aerodynamic performance. SAE Technical Paper 801401 (1980)

12. Calkins, D.E.; Chan, W.T.: CDaero-a parametric aerodynamic drag prediction tool. SAE Technical Paper 980398 (1998)

13. Koromilas, C.; Harris, C.; Sumantran, V.; Pachon, L.; Zeng, S.: Rapid aerodynamic development of two-volume vehicle shapes. SAE Technical Paper 2000-01-0488 (2000)

14. Rho, J.H.; Ku, Y.C.; Lee, D.H.; Kee, J.D.; Kim, K.Y.: Application of modelling function design method to road vehicle aerodynamic optimization in initial design stage. SAE Technical Paper 2009-011166 (2009)

15. Baker, C.J.: A simplified analysis of various types of wind-induced road vehicle accidents. J. Wind Eng. Ind. Aerodyn. 22, 69-85 (1986)

16. Baker, C.J.: Measures to control vehicle movement at exposed sites during windy periods. J. Wind Eng. Ind. Aerodyn. 25(2), 151-161 (1987)

17. Baker, C.J.: High sided articulated road vehicles in strong cross winds. J. Wind Eng. Ind. Aerodyn. 31(1), 67-85 (1988)

18. Coleman, S.A.; Baker, C.J.: High sided road vehicles in cross winds. J. Wind Eng. Ind. Aerodyn. 36(2), 1383-1391 (1990)

19. Baker, C.J.: Ground vehicles in high cross winds part I: steady aerodynamic forces. J. Fluids Struct. 5(1), 69-90 (1991)

20. Baker, C.J.: Ground vehicles in high cross winds part II: unsteady aerodynamic forces. J. Fluids Struct. 5(1), 91-111 (1991)

21. Baker, C.J.: Ground vehicles in high cross winds part III: the interaction of aerodynamic forces and the vehicle system. J. Fluids Struct. 5(2), 221-241 (1991)

22. Coleman, S.A.; Baker, C.J.: The reduction of accident risk for high sided road vehicles in cross winds. J. Wind Eng. Ind. Aerodyn. 44(1-3), 2685-2695 (1992)

23. Baker, C.J.: The behaviour of road vehicles in unsteady cross winds. J. Wind Eng. Ind. Aerodyn. 49(1-3), 439-448 (1993)

24. Baker, C.J.: The quantification of accident risk for road vehicles in cross winds. J. Wind Eng. Ind. Aerodyn. 52, 93-107 (1994)

25. Allen, J.W.: Aerodynamic drag and pressure measurements on a simplified tractor-trailer model. J. Wind Eng. Ind. Aerodyn. 9(12), 125-136 (1981)

26. Modi, V.J.: Moving surface boundary-layer control: a review. J. Fluids Struct. 11(6), 627-663 (1997)

27. Regert, T.; Lajos, T.: Description of flow field in the wheelhouses of cars. Int. J. Heat Fluid Flow 28(4), 616-629 (2007) 
28. Singh, S.N.; Rai, L.; Puri, P.; Bhatnagar, A.: Effect of moving surface on the aerodynamic drag of road vehicles. Proc. Inst. Mech. Eng. D: J. Automob. Eng. 219, 127-134 (2005)

29. Yabin, L.; Tan, L.; Hao, Y.; Xu, Y.: Energy performance and flow patterns of a mixed-flow pump with different tip clearance sizes. Energies 10(2), 191 (2017)

30. Tan, L.; Zhu, B.; Wang, Y.; Cao, S.; Gui, S.: Numerical study on characteristics of unsteady flow in a centrifugal pump volute at partial load condition. Eng. Comput. 32(6), 1549-1566 (2015)

31. Asim, T.; Mishra, R.: Optimal design of hydraulic capsule pipeline transporting spherical capsules. Can. J. Chem. Eng. 94(5), 966-979 (2016)

32. Asim, T.; Mishra, R.: Computational fluid dynamics based optimal design of hydraulic capsule pipelines transporting cylindrical capsules. Int. J. Powder Technol. 295, 180-201 (2016)

33. Asim, T.; Mishra, R.; Abushaala, S.; Jain, A.: Development of a design methodology for hydraulic pipelines carrying rectangular capsules. Int. J. Press. Vessels Pip. 146, 111-128 (2016)

34. Agarwal, V.C.; Mishra, R.: Optimal design of a multi-stage capsule handling multi-phase pipeline. Int. J. Press. Vessels Pip. 75, 27-35 (1998)

35. Mishra, R.; Singh, S.N.; Seshedri, V.: Velocity measurement in solid-liquid flows using an impact probe. Flow Meas. Instrum. 8(3-4), 157-165 (1998)

36. Mishra, R.; Singh, S.N.; Seshedri, V.: Improved model for the prediction of pressure drop and velocity field in multi-sized particulate slurry flow through horizontal pipes. Powder Handl. Process. 10, 279-287 (1998)
37. Mishra, R.; Palmer, E.; Fieldhouse, J.: An optimization study of a multiple-row pin-vented brake disc to promote brake cooling using computational fluid dynamics. Proc. Inst. Mech. Eng. D: J. Automob. Eng. 223(7), 865-875 (2009)

38. Versteeg, H.K.; Malalasekera, W.: An Introduction to Computational Fluid Dynamics. Longman Scientific and Technical, London (1995)

39. Cebeci, T.; Shao, J.P.; Kafyeke, F.; Laurendeau, E.: Computational Fluid Dynamics for Engineers. Horizons Publishing, New York (2005)

40. Lomax, H.; Pulliam, T.H.; Zingg, D.W.: Fundamentals of Computational Fluid Dynamics. Springer, Berlin (2001)

41. Menter, F.R.: Two-equation eddy-viscosity turbulence models for engineering applications. Am. Inst. Aeronaut. Astronaut. 32(8), 1598-1605 (1994)

42. Lasdon, L.S.; Fox, R.L.; Ratner, M.W.: Nonlinear optimization using the generalized reduced gradient method. RAIRO Oper. Res. 8(V3), 73-103 (1974) 